\title{
Investigation on Dynamic Recrystallization Behavior of Martensitic Stainless Steel
}

\author{
Facai Ren, Fei Chen, and Jun Chen \\ National Die and Model CAD Engineering Research Center, Shanghai Jiao Tong University, 1954 Huashan Road, Shanghai 200030, \\ China \\ Correspondence should be addressed to Fei Chen; feechn@gmail.com
}

Received 16 April 2014; Accepted 3 June 2014; Published 9 July 2014

Academic Editor: Pavel Lejcek

Copyright (C) 2014 Facai Ren et al. This is an open access article distributed under the Creative Commons Attribution License, which permits unrestricted use, distribution, and reproduction in any medium, provided the original work is properly cited.

The hot deformation behavior of $\mathrm{X} 20 \mathrm{Cr} 13$ martensitic stainless steel was studied using the hot compression flow curves corresponding to the temperature range of $900-1150^{\circ} \mathrm{C}$ under strain rates from 0.01 to $10 \mathrm{~s}^{-1}$. A new mathematical model to estimate the flow stress under hot deformation conditions up to the peak of the flow curves was developed. The critical strains for initiation of dynamic recrystallization were also derived by the developed model. Furthermore, the effects of Zener-Hollomon parameter on the characteristic points of the flow curves were studied using the power law relation. The deformation activation energy obtained for this steel was $359.4 \mathrm{~kJ} / \mathrm{mol}$ in the temperature range from $900^{\circ} \mathrm{C}$ to $1150^{\circ} \mathrm{C}$. At the same time, the Avrami kinetic equation of dynamic recrystallization for $\mathrm{X} 20 \mathrm{Cr} 13$ steel and the recrystallized grain size model were also established. Good agreement was obtained between the predictions and the experimental values.

\section{Introduction}

Dynamic recrystallization (DRX) is one of the most important restoration mechanisms during hot deformation, affecting the final microstructure, and therefore, DRX has been increasingly used to control the microstructure evolution to obtain the finer grains. Due to the growing importance of hot deformation in metal forming there is an increasing interest in understanding the critical conditions in which DRX is initiated during hot deformation, such as multipass hot rolling and multipass stretching processes, as it determines if metadynamic recrystallization (MDRX) occurs during interpass time $[1,2]$. Typically, DRX takes place by the appearance of a peak in the stress-strain curves under the condition of a constant strain rate. However, DRX actually occurs before the strain peak corresponding to the stress peak. This threshold strain is known as the critical strain for initiation of DRX. The critical strain for DRX mainly depends on the chemical composition of the material under consideration, the grain size prior to deformation, and the deformation schedule $[3,4]$. Generally speaking, there are mainly two methods to determine the critical strain: (1) mathematical analysis for the work hardening $(\theta=d \sigma / d \varepsilon)$ curves [2,3,5-10] and
(2) metallography investigation $[1,11]$. Besides all of these, there are also some other attempts to predict the initiation of DRX. For example, an equation for the critical strain for onset of DRX was developed by recasting an empirical kinetics equation of static recrystallization (SRX) [12]. On the basis of a dislocation density work hardening model, the critical strain for initiation of DRX was investigated by Gottstein et al. [13].

Martensitic stainless steels are usually used for manufacturing components with excellent mechanical properties and moderate corrosion resistance such as turbine blades, steam generators, pressure vessels, and medical treatments. The annual consumption of stainless steel has increased at a compound growth rate of $5 \%$ over the last 20 years, surpassing the growth rate of other materials [14]. X20Cr13 stainless steel, which is widely used in the manufacture of low pressure steam turbine moving blades and low pressure bypass valves of fossil fuel and nuclear power plants, has a martensitic microstructure containing spheroidized carbides [15]. However, there is almost no information on the hot deformation behavior of this important engineering steel. Thus, the main objective of the present work is to study the 


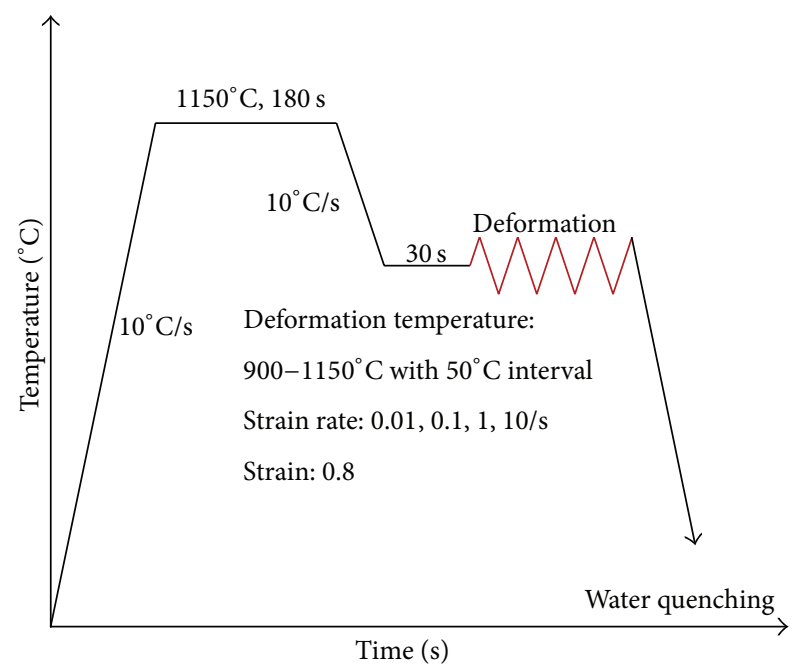

FIGURE 1: Experimental procedure for hot compression tests.

effect of deformation temperature and strain rate on the compressive deformation characteristics of X20Cr13 martensitic stainless steel by hot compression tests. At the same time, a new mathematical model was proposed to estimate the flow stress under hot deformation conditions up to the peak of the flow curves. The critical strains for dynamic recrystallization were also derived by using the developed model.

\section{Experimental Material and Procedures}

X20Cr13 martensitic stainless steel with a chemical composition (wt.\%) of 0.19C-0.131Cr-0.18Si-0.16Mn-0.02P-0.004S(bal.)Fe was used in this investigation. Cylindrical specimens for hot compression test with a diameter of $10 \mathrm{~mm}$ and a height of $15 \mathrm{~mm}$ were machined from the as-received hot forged bar according to the ASTM E209 standard [16]. The hot compression tests were carried out according to the schedule illustrated in Figure 1 on a Gleeble-1500D thermomechanical simulator. The specimens were heated to $1150^{\circ} \mathrm{C}$ at a heating rate of $10^{\circ} \mathrm{C} / \mathrm{s}$ and held for $3 \mathrm{~min}$ and then cooled to the test temperature at the cooling rate of $10^{\circ} \mathrm{C} / \mathrm{s}$. Then, the specimens were held at the forming temperature for 30 seconds to get a uniform temperature distribution. The tests were performed at $900^{\circ} \mathrm{C}, 950^{\circ} \mathrm{C}, 1000^{\circ} \mathrm{C}, 1050^{\circ} \mathrm{C}, 1100^{\circ} \mathrm{C}$, and $1150^{\circ} \mathrm{C}$ and strain rates of $0.01 \mathrm{~s}^{-1}, 0.1 \mathrm{~s}^{-1}, 1 \mathrm{~s}^{-1}$, and $10 \mathrm{~s}^{-1}$, respectively. The true stress-strain curves were recorded automatically in the isothermal compression process. All specimens were compressed to a true stain of 0.8 and then instantly quenched into cold water in order to preserve the hot deformation microstructure. In order to minimize the friction between the specimen and the die during hot compression, the flat ends of the specimens were covered by a lubricant consisting of graphite powder and machine oil. Finally, the quenched specimens were sliced along the axial section. The sections were polished and etched with $10 \%$ sulphuric acid aqueous solution and optical micrographs were recorded. The microstructure evolution was observed using Axio Imager M2m (Zeiss). The grain size was determined using the line intercept method in two vertical directions as per ASTM E112-88 [17]. The distance between adjacent parallel lines was $10 \mu \mathrm{m}$, and the total true length of the measuring line exceeded $1000 \mathrm{~mm}$. The average grain size characterized as equivalent circle diameter was calculated by multiplying the intercept length by a factor of $(4 / \pi)^{1 / 2}$. The grain size distribution was obtained by dividing the number of grains in a certain range of the average grain diameter by the total number of measured grains. The microimage analysis and process software were used to analyze the optical micrographs.

\section{Results and Discussion}

3.1. Hot Deformation Flow Curves. The true stress-strain curves obtained from hot compression tests at different deformation temperatures and strain rates are shown in Figure 2. It is obvious that the true stress-strain curves are sensitive to deformation temperature as shown in Figure 2(a). The flow stress will decrease with the increase of deformation temperature. The reason mainly has the following aspects: the increase of deformation temperature increases the rate of the vacancy diffusion, cross-slip of screw dislocations, and climb of edge dislocations $[18,19]$. It also can be found that the dynamic softening phenomenon is especially sensitive to the strain rate from Figure 2(b). At the strain rates of $0.01 \mathrm{~s}^{-1}$ and $0.1 \mathrm{~s}^{-1}$, most of the curves show a single peak followed by a decrease of stress and finally reach a plateau, which implies the occurrence of the DRX phenomenon. At the strain rates of $1 \mathrm{~s}^{-1}$ and $10 \mathrm{~s}^{-1}$ for all the deformation temperatures, the true stress-strain curves obviously show dynamic recovery character. It can be explained that at higher strain rates, there is no enough time for the nucleation and growth of DRX grains and dislocation annihilation [20].

3.2. Calculation of Activation Energy for Hot Deformation. The relationship among the flow stress, the deformation temperature, and the strain rate in the plastic deformation of metallic materials can be expressed by using [21]

$$
Z=\dot{\varepsilon} \exp \left(\frac{Q}{R T}\right)=f(\sigma) \text {. }
$$

In this equation, the $Z$ parameter is the temperaturecompensated strain rate, $\dot{\varepsilon}$ is strain rate, $\sigma$ is stress, $Q$ is the activation energy of deformation, $R$ is gas constant (8.314 $\mathrm{Jmol}^{-1} \mathrm{~K}^{-1}$ ), and $T$ is temperature. It is obvious that the $Z$ parameter is also considered as a function of stress. Based on this equation, the $Z$ parameter can be related to the flow stress in different ways:

$$
\begin{gathered}
Z=f(\sigma)=A^{\prime} \sigma^{n^{\prime}}, \\
Z=f(\sigma)=A^{\prime \prime} \exp (\beta \sigma), \\
Z=f(\sigma)=A[\sinh (\alpha \sigma)]^{n},
\end{gathered}
$$

where $A^{\prime}, A^{\prime \prime}, A, n^{\prime}, n, \beta$, and $\alpha\left(\alpha \approx \beta / n^{\prime}\right)$ are material constants. The stress multiplier $\alpha$ is an adjustable constant 


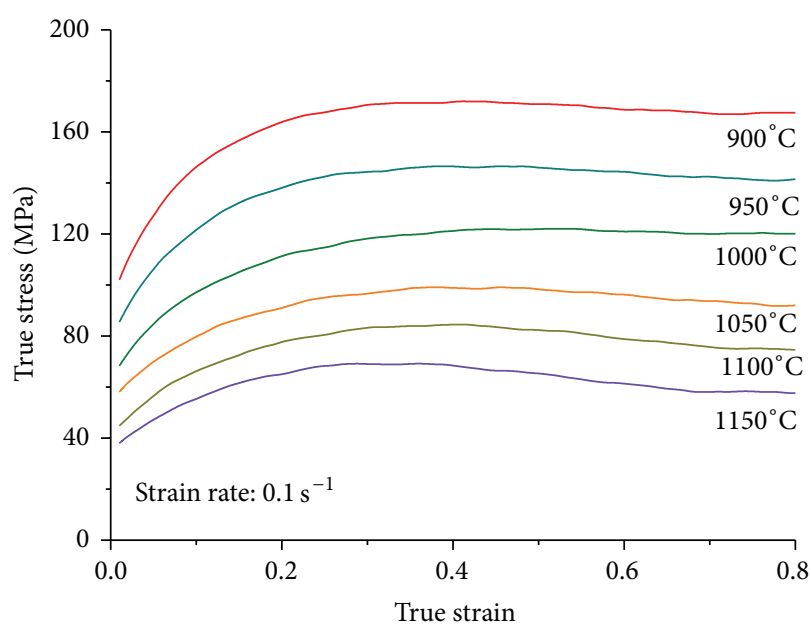

(a)

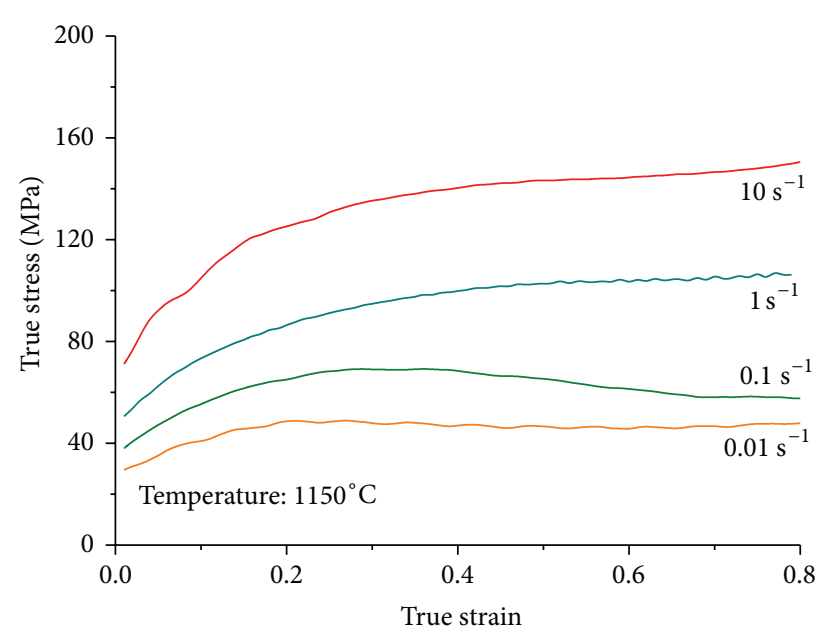

(b)

Figure 2: Typical true stress-strain curves for X20Cr13 martensitic stainless steel under different deformation conditions.

which brings $\alpha \sigma$ into the correct range to make constant $T$ curves in $\ln \dot{\varepsilon}$ versus $\ln (\sinh (\alpha \sigma))$ plots linear and parallel $[22,23]$. The power law description of stress (2) is preferred for low stress level while exponential law (3) is suitable for high stress level. However, the hyperbolic sine law (4) can be used for a wide range of temperatures and strain rates.

At a certain deformation temperature, substituting the $f(\sigma)$ into (1) and taking the logarithm of both sides and rearranging, respectively, the following expressions can be derived:

$$
\begin{gathered}
\ln \dot{\varepsilon}=n^{\prime} \ln \sigma+\ln A^{\prime}-\left(\frac{Q}{R T}\right), \\
\ln \dot{\varepsilon}=\beta \sigma+\ln A^{\prime \prime}-\left(\frac{Q}{R T}\right), \\
\ln \dot{\varepsilon}=n \ln (\sinh (\alpha \sigma))+\ln A-\left(\frac{Q}{R T}\right) .
\end{gathered}
$$

The description of flow stress by (1) is incomplete because of lacking of strain. Characteristic stresses such as peak, steady, or the stress corresponding to a specific strain can be used for the calculation of material constants. For the fixed deformation temperature and strain, by differentiating (5), (6), and (7), respectively, the value of $n^{\prime}, \beta$, and $n$ can be determined by using the following equations:

$$
\begin{gathered}
n^{\prime}=\left[\frac{\partial \ln \dot{\varepsilon}}{\partial \ln \sigma}\right]_{T} \\
\beta=\left[\frac{\partial \ln \dot{\varepsilon}}{\partial \sigma}\right]_{T} \\
n=\left[\frac{\partial \ln \dot{\varepsilon}}{\partial \ln (\sinh (\alpha \sigma))}\right]_{T} .
\end{gathered}
$$

In this study, the relationships between the flow stress and stain rate are obtained by substituting the stress values under the strain rates of $0.01 \mathrm{~s}^{-1}, 0.1 \mathrm{~s}^{-1}, 1 \mathrm{~s}^{-1}$, and $10 \mathrm{~s}^{-1}$ and deformation temperatures of $900^{\circ} \mathrm{C}$ to $1150^{\circ} \mathrm{C}$ at the interval of $50^{\circ} \mathrm{C}$ corresponding to the true strain of 0.5 into (8), (9), and (10). Then the values of $\beta$ and $n^{\prime}$ can be calculated as the mean slops of the plot of $\ln \dot{\varepsilon}$ against $\sigma$ and $\ln \dot{\varepsilon}$ against $\ln \sigma$, respectively, as shown in Figures 3(a) and 3(b). The values of $\beta$ and $n^{\prime}$ are $0.0559 \mathrm{MPa}^{-1}$ and 7.383 , respectively. This gives the value of $\alpha=\beta / n^{\prime}=0.00757 \mathrm{MPa}^{-1}$. According to (10), the mean slop and intercept of $\ln \dot{\varepsilon}$ against $\ln (\sinh (\alpha \sigma))$ can be used for calculating the values of $n$ and $\ln A$ (Figure 3(c)), respectively. The $n$ and $\ln A$ are calculated as 5.366 and 31.341, respectively. So the value of $A$ is $4.06 \times 10^{13}$. For a constant strain rate, partial differentiation of (7) gives

$$
Q=n R\left[\frac{\partial \ln (\sinh (\alpha \sigma))}{\partial(1 / T)}\right]_{\dot{\varepsilon}}
$$

The value of activation energy is calculated as the average of slopes of the plot of $\ln (\sinh (\alpha \sigma))$ against $1 / T$ (Figure 3(d)). The value of $Q$ is determined as $359.4 \mathrm{~kJ} \mathrm{~mol}^{-1}$.

3.3. Characteristic Points of Flow Curves. The characteristic points of flow curves were determined by using the methods shown in [23] and subsequently plotted in Figure 4 on a logarithmic scale with respect to $Z$ using power relations.

Regression analysis of these curves resulted in the following equations:

$$
\begin{aligned}
& \varepsilon_{p}=0.0128 \times Z^{0.1082}, \\
& \sigma_{p}=1.0294 \times Z^{0.1509}, \\
& \varepsilon_{s}=0.0058 \times Z^{0.1615}, \\
& \sigma_{s}=2.1179 \times Z^{0.1468},
\end{aligned}
$$

where $\varepsilon_{p}$ is the peak strain, $\sigma_{p}$ is the peak stress, $\varepsilon_{s}$ is the steady-state strain, and $\sigma_{s}$ is the steady-state stress. The $Z$ exponent of 0.1082 in (12) is relatively consistent with the 

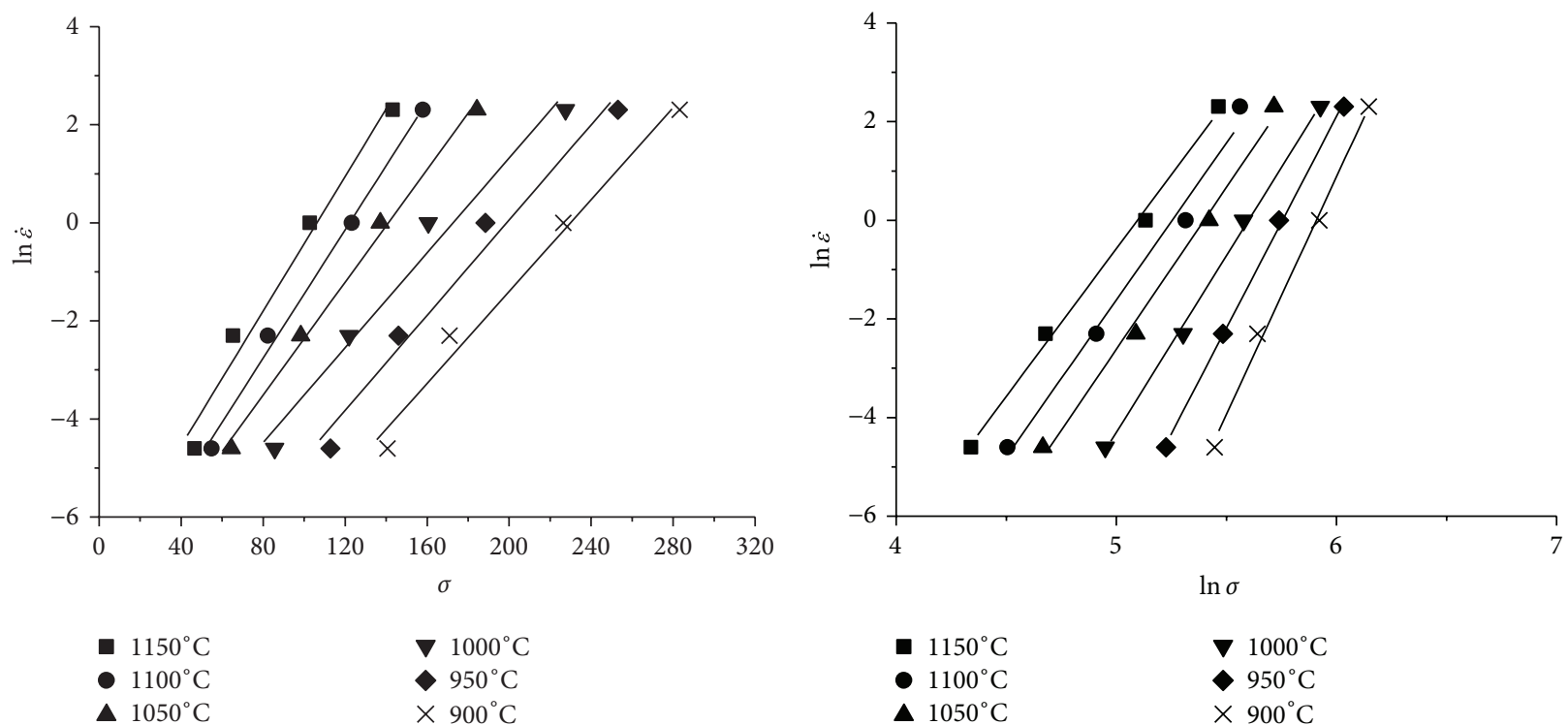

(a)

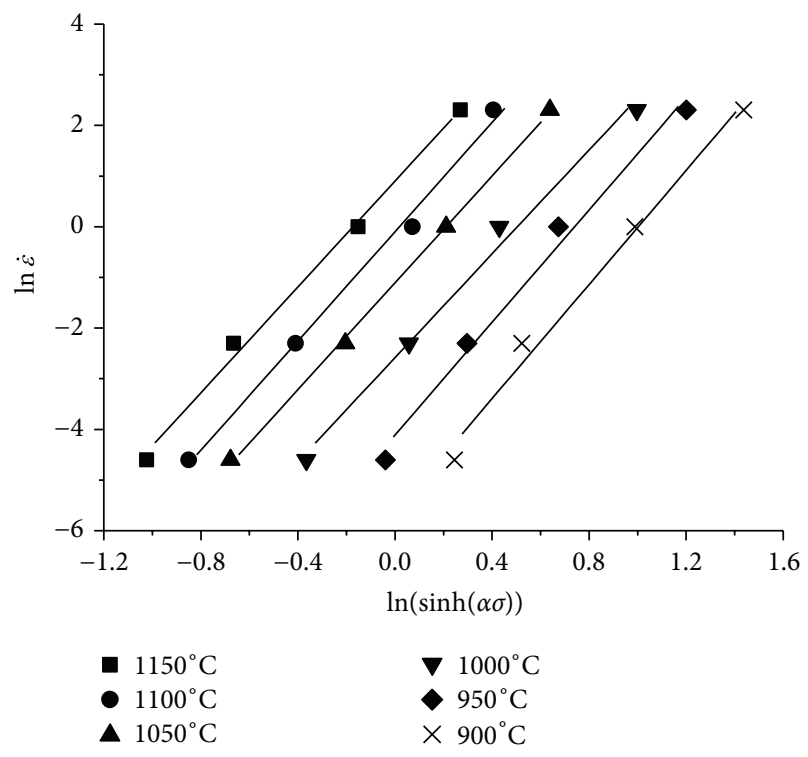

(c) (b)

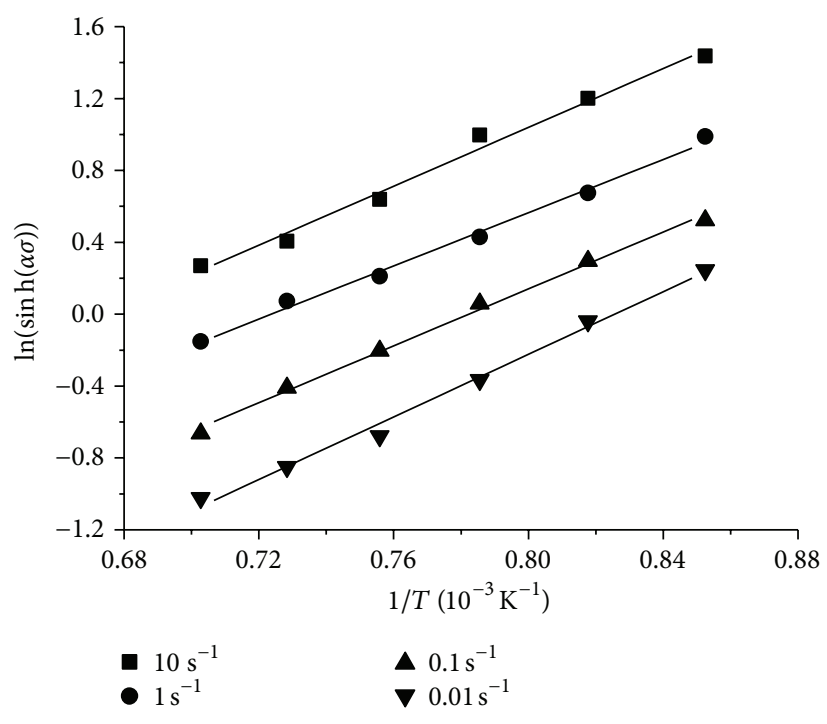

(d)

FIGURE 3: Relationships between (a) $\ln \dot{\varepsilon}$ and $\sigma$, (b) $\ln \dot{\varepsilon}$ and $\ln \sigma$, (c) $\ln \dot{\varepsilon}$ and $\ln (\sinh (\alpha \sigma))$, and (d) $\ln (\sinh (\alpha \sigma))$ and $1 / T$.

classical literature data which has a value between 0.12 and 0.22 . Meanwhile, the $Z$ exponent of 0.1468 for describing stresses is consistent with previous reports on low carbon microalloyed steel [24] and medium carbon microalloyed steel [23].

3.4. Prediction of Critical Condition for Onset of Dynamic Recrystallization. The effect of temperature and strain rate on the flow curves of X20Cr13 steel is illustrated in Figure 2. As can be seen from the figure, the flow curves evidently exhibit stress peak at the temperatures and strain rates investigated. It suggests that DRX has been initiated. The curves $u\left(u=\sigma / \sigma_{p}\right)-v\left(v=\varepsilon / \varepsilon_{p}\right)$ from the present flow curves are displayed in Figure 5. It can be found that the $u-v$ plots for different $Z$ values basically fall on a single curve. In other words, the evolution function $f(v)$ within the specified $Z$ range can be recognized to be $Z$ value independent of $\mathrm{X} 20 \mathrm{Cr} 13$ steel, the characteristic of which is very similar with the characteristic of the plain low carbon aluminum killed (AK) steel investigated in [2]. Therefore, once the evolution function $f(v)$ has been established, the flow stress up to the peak at any strain, strain rate, and temperature can be calculated by using the developed function. In the present study, the flow curve up to the peak stress was modeled using the newly developed equation as shown below:

$$
\frac{\sigma}{\sigma_{p}}=1-\exp \left(\psi\left(\frac{\varepsilon}{\varepsilon_{p}}\right)^{\zeta}\right),
$$




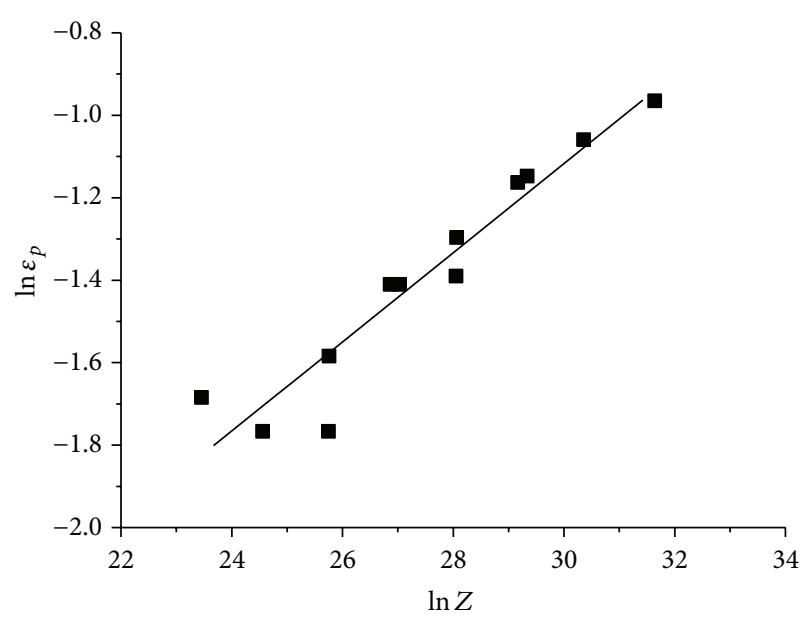

- Linear fit

(a)

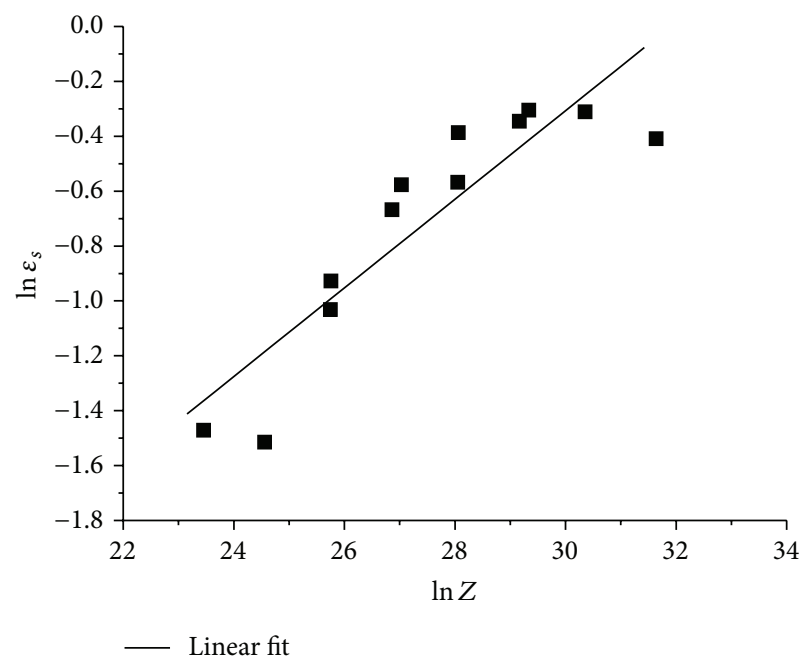

(c)

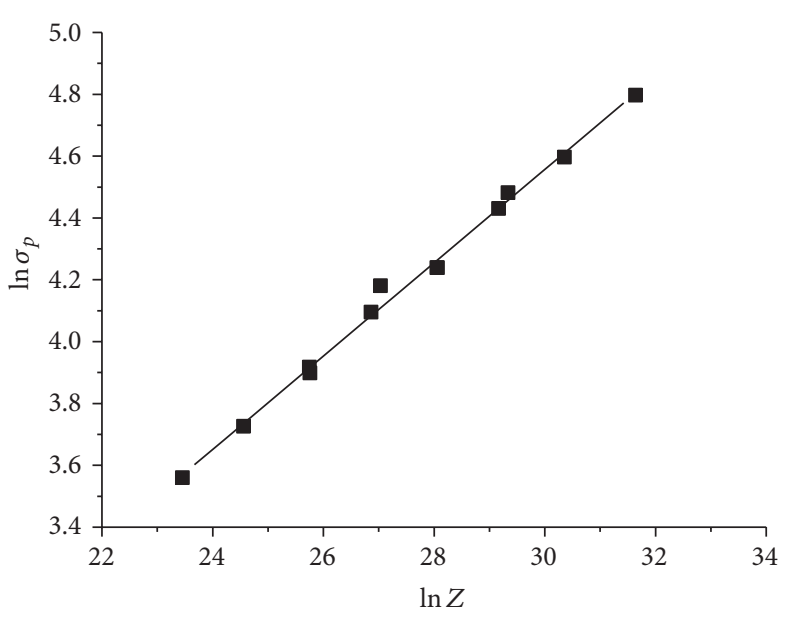

- Linear fit

(b)

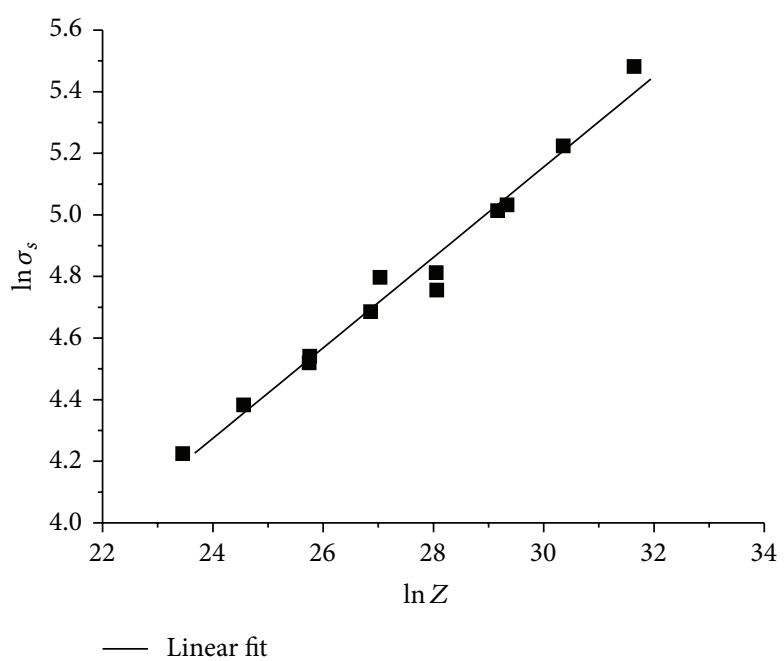

(d)

Figure 4: Relationships between (a) $\ln \varepsilon_{p}$ and $\ln Z$, (b) $\ln \sigma_{p}$ and $\ln Z$, (c) $\ln \varepsilon_{s}$ and $\ln Z$, and (d) $\ln \sigma_{s}$ and $\ln Z$.

where $\sigma$ is stress, $\sigma_{p}$ is peak stress, $\varepsilon$ is strain, $\varepsilon_{p}$ is peak strain, and $\psi$ and $\zeta$ are two material constants. It should be mentioned that it is the first constitutive equation with this kind of parameters. These variables are interdependent, which can be obtained by the method of least squares. A program was developed to determine $\psi$ and $\zeta$ in MATLAB (see "Appendix A"). The strain hardening rate $\theta$ can be obtained as the derivative of (16):

$$
\theta=\frac{d \sigma}{d \varepsilon}=\frac{-\sigma_{p} \zeta \psi}{\varepsilon_{p}} \exp \left(\psi\left(\frac{\varepsilon}{\varepsilon_{p}}\right)^{\zeta}\right)\left(\frac{\varepsilon}{\varepsilon_{p}}\right)^{\zeta-1}
$$

Recently, Ryan and McQueen [25], Poliak and Jonas [2], and Najafizadeh and Jonas [6] pointed that the initiation of DRX is associated with the inflection point in the curves of the strain hardening rate $\theta$ versus flow stress $\sigma$. Mathematically, a minimum point of $d \theta / d \sigma-\sigma$ is equivalent to a null value of the second derivative of $\theta$ with respect to $\sigma$ and indicates the inflection of $\theta-\sigma$ curve [2]:

$$
\left.\frac{d^{2} \theta}{d \sigma^{2}}\right|_{\text {critical strain }}=0
$$

Therefore, construct the second differential of strain hardening rate and let the second differential be zero, and the turning point of (17) will be obtained:

$$
\begin{aligned}
& \frac{d^{2} \theta}{d \sigma^{2}} \\
& =\frac{\left(\psi \zeta(\zeta-1) / \varepsilon_{p}^{2}\right)\left(\varepsilon_{c} / \varepsilon_{p}\right)^{\zeta-2}-\left((\zeta-1) / \varepsilon_{p}^{2}\right)\left(\varepsilon_{c} / \varepsilon_{p}\right)^{-2}}{\left(\sigma_{p} \zeta \psi / \varepsilon_{p}\right) \exp \left(\psi\left(\varepsilon_{c} / \varepsilon_{p}\right)^{\zeta}\right)\left(\varepsilon_{c} / \varepsilon_{p}\right)^{\zeta-1}}=0 .
\end{aligned}
$$




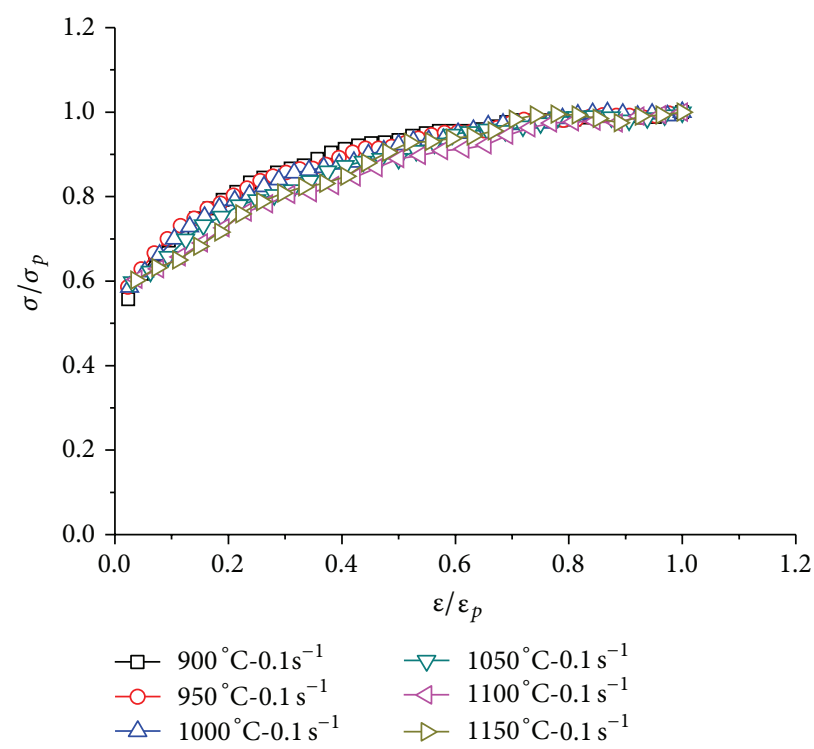

FIGURE 5: Relationship between $\sigma / \sigma_{p}$ and $\varepsilon / \varepsilon_{p}$ under different deformation conditions.

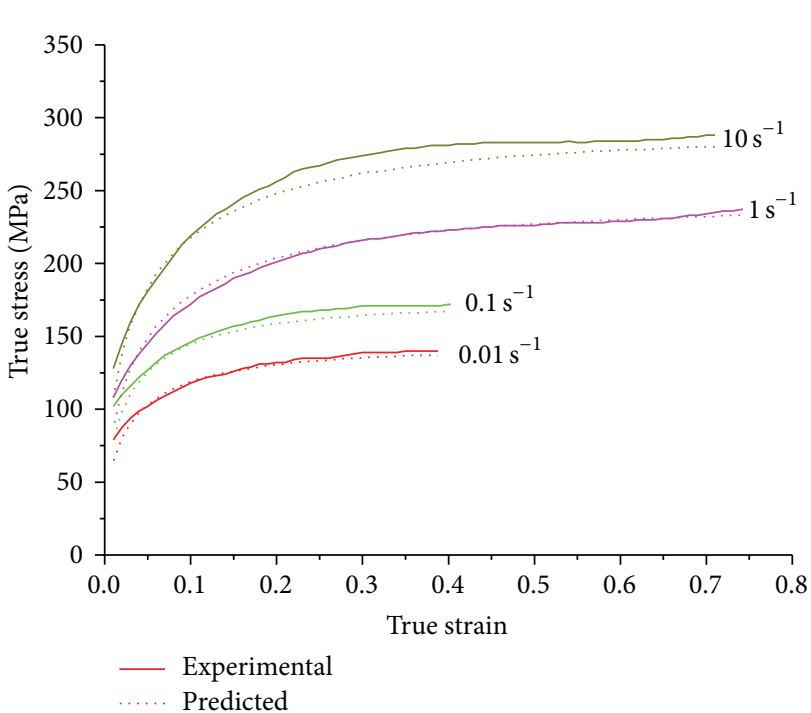

(a) $900^{\circ} \mathrm{C}$

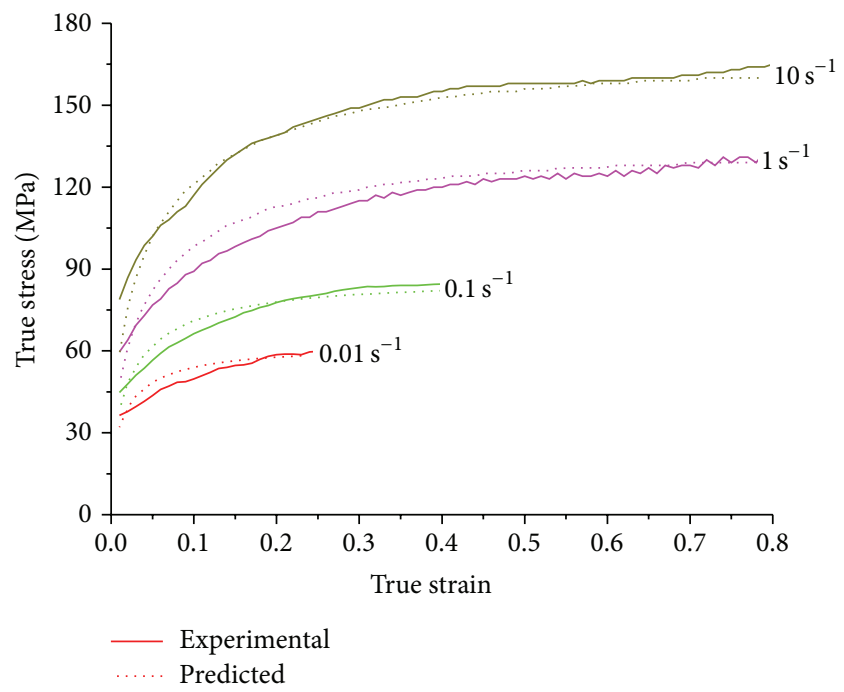

(c) $1100^{\circ} \mathrm{C}$

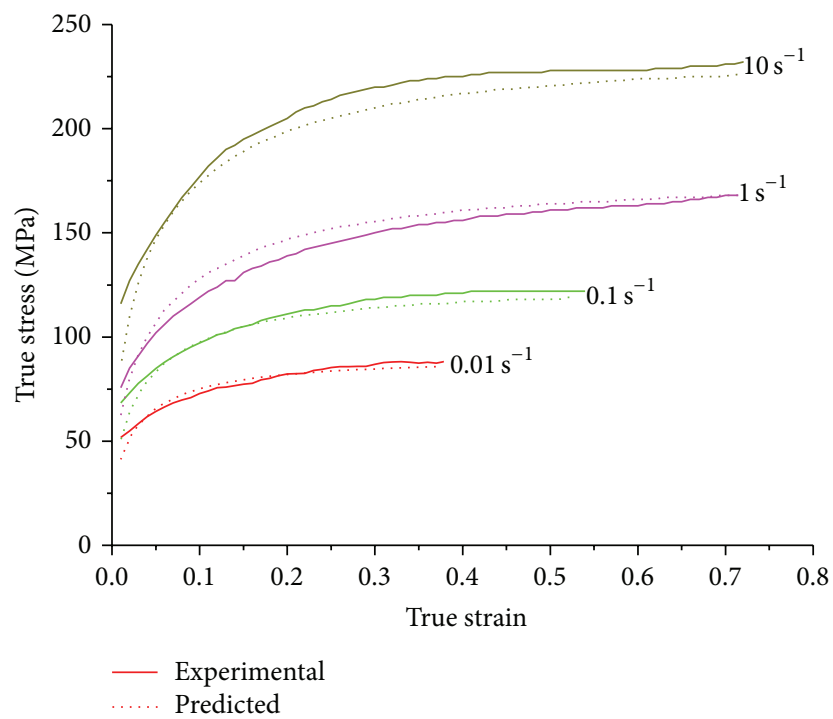

(b) $1000^{\circ} \mathrm{C}$

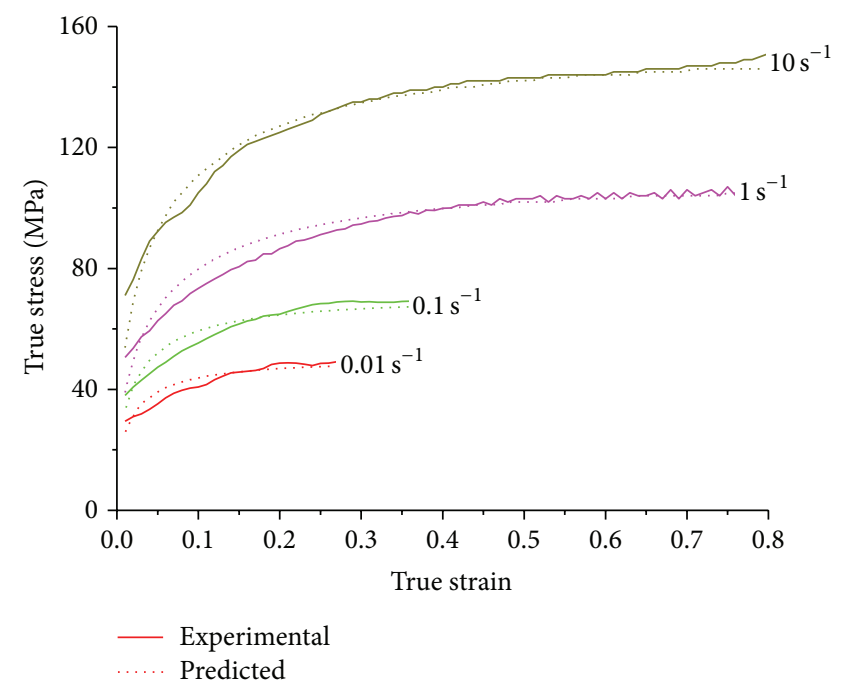

(d) $1150^{\circ} \mathrm{C}$

FIGURE 6: Comparison of the predicted value by the model with the experimental data. 


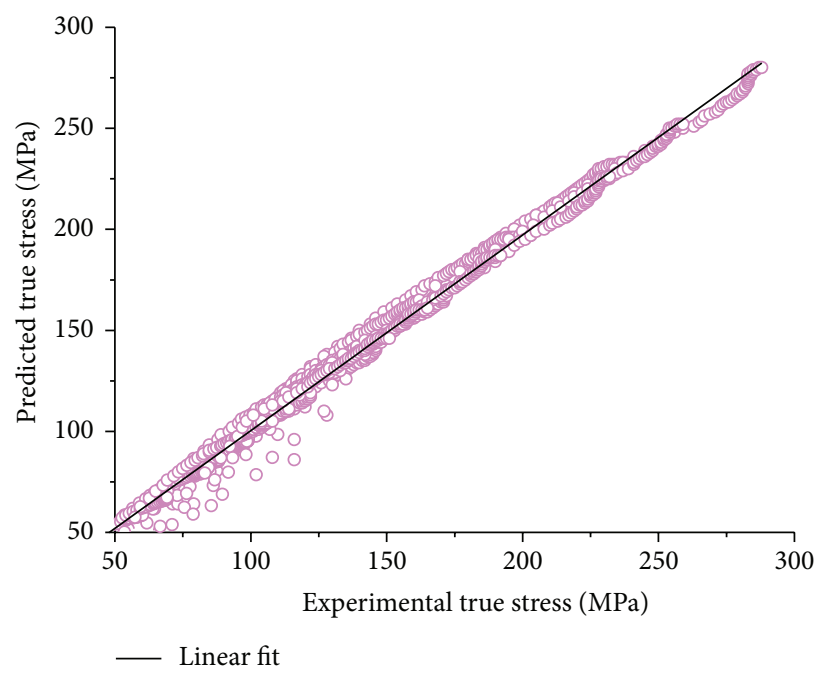

\begin{tabular}{|l|l|l|l|}
\hline Equation & $y=a+b * x$ & & \\
\hline Adj. $R^{2}$ & 0.99404 & & \\
\hline & & Value & Standard error \\
\hline Predicted & Intercept & 3.57772 & 0.31137 \\
\hline Predicted & Slope & 0.96772 & 0.00202 \\
\hline
\end{tabular}

FIGURE 7: The plot of predicted versus experimental stress for the developed model.

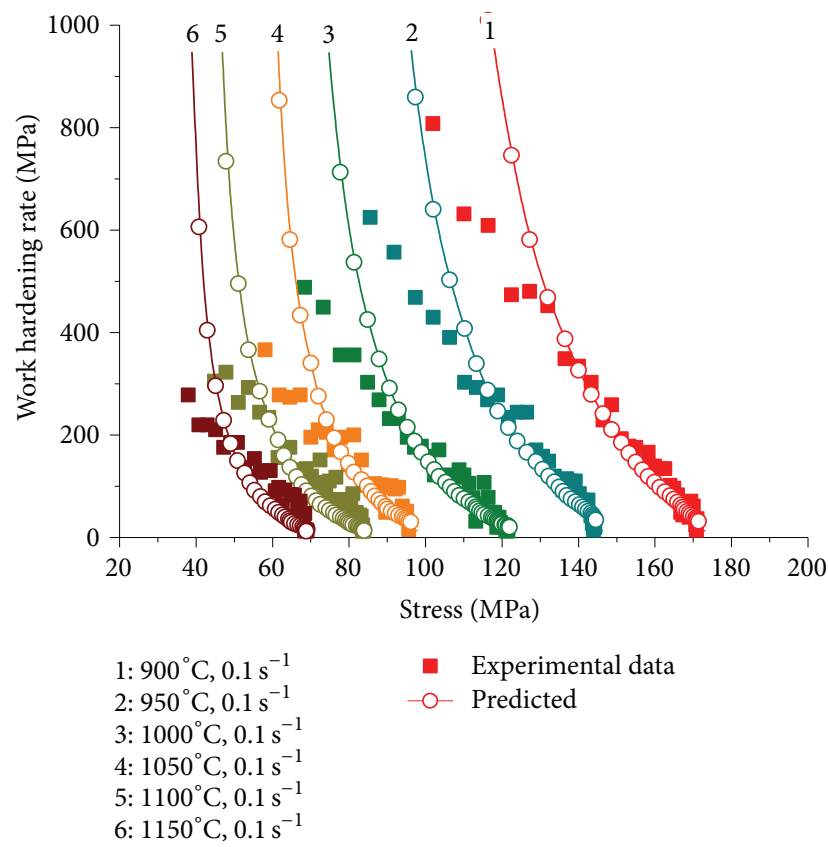

FIGURE 8: The plot of $\theta-\sigma$ for different deformation conditions.

The solution of (19) is as follows (the derivations process is placed in “Appendix B"):

$$
\frac{\varepsilon_{c}}{\varepsilon_{p}}=\left(\frac{1}{\psi \zeta}\right)^{1 / \zeta}
$$

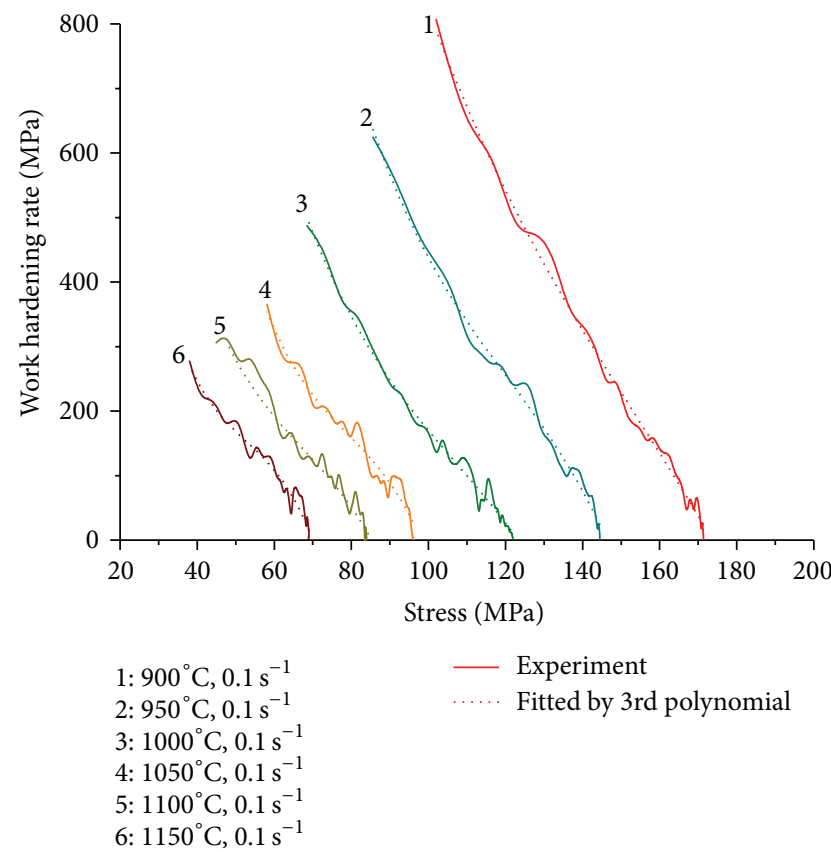

FIgURE 9: The $\theta-\sigma$ curve and its corresponding third order polynomial.

where $\varepsilon_{c}$ is the critical strain for DRX. The material constants values of the steel are used for further calculations which are determined to be -3.6029 and 0.4787 for $\psi$ and $\zeta$, respectively. On the other hand, utilizing (16), flow stress is calculated for all different hot deformation conditions and compared with experimental results. This comparison is illustrated in 


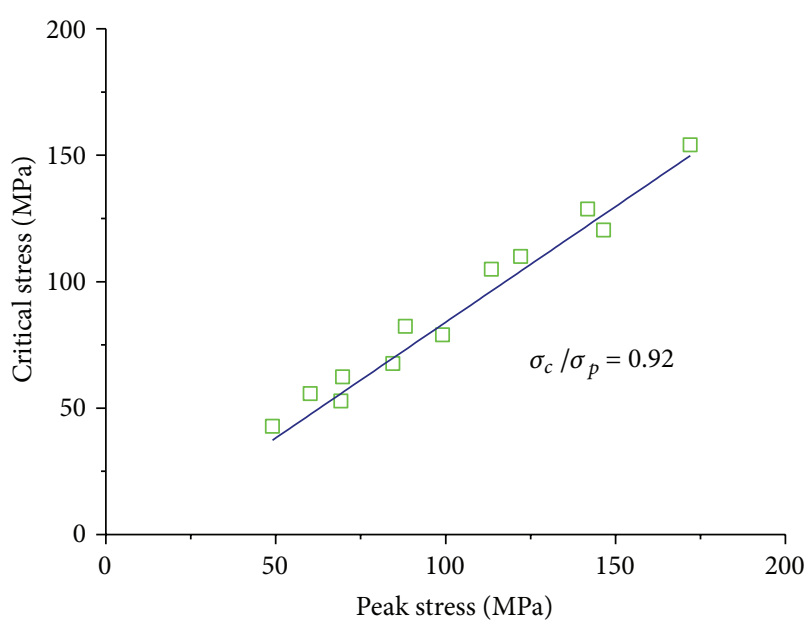

$\square \quad$ Critical stress

\section{— Linear fit}

\begin{tabular}{|l|c|l|c|}
\hline Equation & \multicolumn{2}{|c|}{$y=a+b * x$} & \\
\hline Adj. $R^{2}$ & 0.98162 & & \\
\hline & & Value & Standard \\
\hline Critical stress & Critical stress & -7.57 & 5.79188 \\
\hline Critical stress & Critical stress & 0.915 & 0.05105 \\
\hline
\end{tabular}

(a)

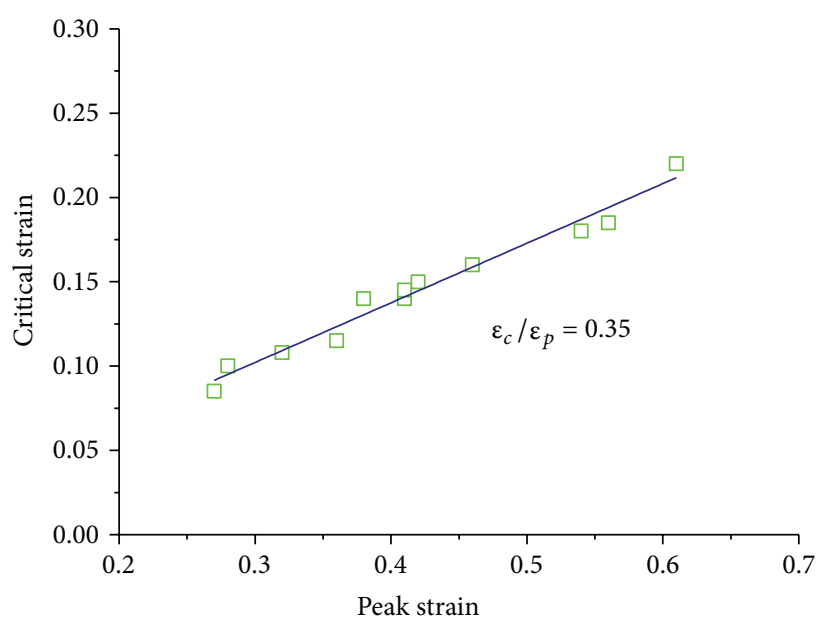

$\square \quad$ Exclude from analysis

_ Linear fit

\begin{tabular}{|l|l|l|c|}
\hline Equation & \multicolumn{2}{|c|}{$y=a+b * x$} & \\
\hline Adj. $R^{2}$ & 0.9684 & & \\
\hline & & Value & Standard $E$ \\
\hline Critical strain & Intercept & -0.003 & 0.00828 \\
\hline Critical strain & Slope & 0.353 & 0.01922 \\
\hline
\end{tabular}

(b)

FIGURE 10: Critical stress and strain curves.

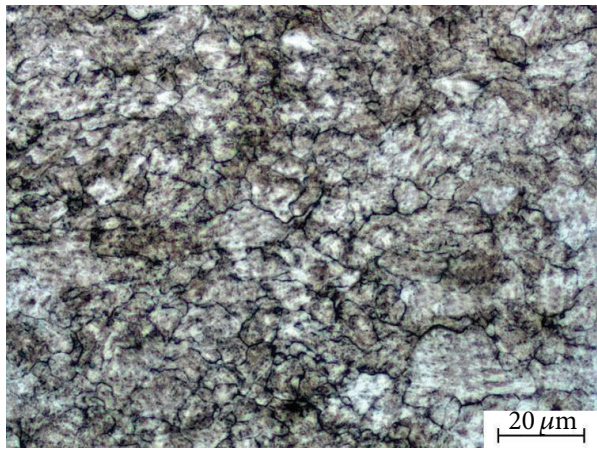

(a)

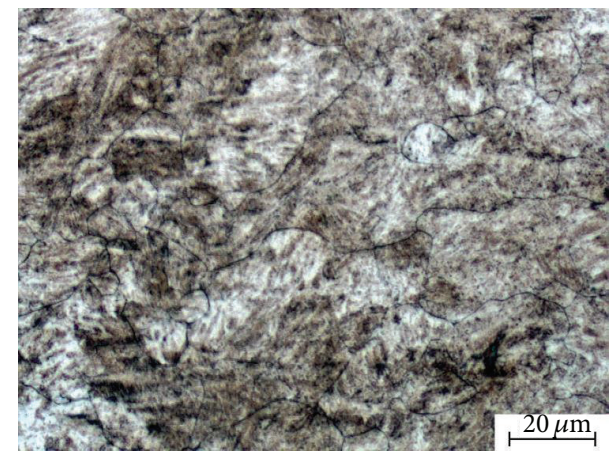

(b)

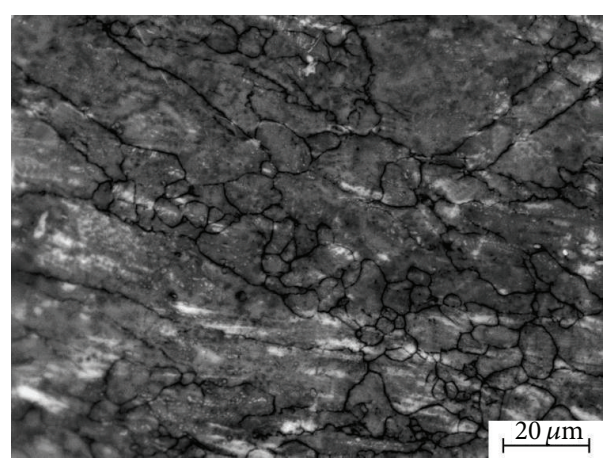

(c)

Figure 11: The microstructure of specimens deformed at (a) $T=1000^{\circ} \mathrm{C}, \dot{\varepsilon}=0.1 \mathrm{~s}^{-1}$, (b) $T=1100^{\circ} \mathrm{C}, \dot{\varepsilon}=0.1 \mathrm{~s}^{-1}$, and (c) $T=1000^{\circ} \mathrm{C}, \dot{\varepsilon}=10 \mathrm{~s}^{-1}$. 
Figures 6(a)-6(d), which demonstrates that the calculated values basically are in accordance with the experimental flow curves by the presented model. From Figure 7, it can be seen that the value of the correlation coefficient is 0.9940 . Figure 8 shows the plot of $\theta-\sigma$ for different deformation conditions. In the figure, (17) is plotted for a comparison with experimental data. The results show a good agreement between the predicted and the experimental results.

Najafizadeh and Jonas suggested that the $\theta-\sigma$ curve can be represented by a third order equation up to the peak stress [6]. By this method, the critical stress for the onset of DRX is presented by the relationship $\sigma_{c}=-B_{2} / 3 B_{1}$, where $B_{1}$ and $B_{2}$ are two of the four coefficients of the third order equation. At the same time, the value of critical strain for initiation of DRX is determined by using the flow curve. Therefore, for each deformation condition, the strain hardening rate is plotted against flow stress and the third order equation that best fits the experimental $\theta-\sigma$ data from zero to the peak stress is obtained. Figure 9 shows the $\theta-\sigma$ curve and its corresponding third order polynomial. As can be seen, the 3rd curves have a good fit as previously demonstrated by Najafizadeh and Jonas [6]. Utilizing the flow curves, the values of critical stress/strain were determined. Meanwhile, the relationship between critical strain and peak strain was determined. The results are shown in Figure 10. According to Figure 10, the strain ratio $\varepsilon_{c} / \varepsilon_{p}$ is 0.35 . Using (20) the value of $\varepsilon_{c} / \varepsilon_{p}$ is determined to be 0.32 which is basically close to the experimental value. It proves the applicability of the inflection analysis for calculation of critical strain by using the newly developed equations (16)-(20).

Therefore, the critical strains for initiation of dynamic recrystallization predicted by the newly developed method can be expressed as

$$
\varepsilon_{c}=0.32 \varepsilon_{p}=0.004096 \times Z^{0.1082} .
$$

It is observed that the present investigation indicates that the dynamic recrystallization occurs when the normalized strain reaches to the value of about 0.32 . However, this deviates from the previous studies on steels which has been evaluated to be $0.4-0.8$. It should be mentioned that, for some grades such high carbon steel, the low value of 0.32 has also been reported [26].

3.5. DRX Microstructures. The microstructure of X20Cr13 steel during hot compression is strongly influenced by the deformation temperature and the strain rate. Figures 11(a) and 11(b) illustrate the optical deformed microstructures of the test steel after deformation at strain rate of $0.1 \mathrm{~s}^{-1}$ and the temperature of $1000^{\circ} \mathrm{C}$ and $1100^{\circ} \mathrm{C}$, respectively. It can be easily found that the original coarse grains are heavily elongated along the deformation direction at a relatively low temperature when the strain reaches 0.8. Meanwhile, microstructural examination of the specimen deformed at $1100^{\circ} \mathrm{C}$ and $0.1 \mathrm{~s}^{-1}$ (Figure 11(b)) revealed that DRX occurs almost completely. In other words, dynamic recrystallization occurs more easily at high deformation temperature and relatively low strain rate. However, at strain rates greater than $1 \mathrm{~s}^{-1}$, the initial grains are elongated along the deformation direction and DRX begins to occur as shown in Figure 11(c) when the strain reaches 0.8 at the temperature of $1000^{\circ} \mathrm{C}$. Figures 12(a)-12(e) show the optical microstructures of the test steel after deformation at strain rate of $0.01 \mathrm{~s}^{-1}$ under the temperatures of $950^{\circ} \mathrm{C}, 1000^{\circ} \mathrm{C}, 1050^{\circ} \mathrm{C}, 1100^{\circ} \mathrm{C}$, and $1150^{\circ} \mathrm{C}$, respectively. It is obvious that the dynamic recrystallized grain size is refined with decreasing the deformation temperature. The average grain sizes are measured as $17 \mu \mathrm{m}$, $24 \mu \mathrm{m}, 31 \mu \mathrm{m}, 37 \mu \mathrm{m}$, and $59 \mu \mathrm{m}$ for the forming temperatures of $950^{\circ} \mathrm{C}, 1000^{\circ} \mathrm{C}, 1050^{\circ} \mathrm{C}, 1100^{\circ} \mathrm{C}$, and $1150^{\circ} \mathrm{C}$, respectively. This is mainly because lower temperature can lead to higher deformation stored energy, refining dynamic recrystallized grain size $[18,19]$.

3.6. DRX Kinetics. Hot deformation in metals occurs by the movement of an increasing number of dislocations on specific crystal planes. The occurrence of work hardening therefore implies that, as the true strain is increased, it becomes more difficult either to generate or to move the relevant dislocations. It is generally accepted that only when dislocation density or strain reaches a critical value, dynamic recrystallization can occur during hot deformation. With the strain increasing, when multiplication of dislocation due to continued deformation and annihilation of dislocation due to dynamic softening are in dynamic balance, flow stress would keep constant, and deformation of metals would come to a steady stage in which complete dynamic recrystallization grains have equiaxed shape and keep constant size. In general, whatever technique is used, studies of dynamic recrystallization show that it progresses in a sigmoidal manner with respect to time. The basic characteristic of DRX kinetics is that there is an initial incubation period which is followed by a rate of change which is initially slow, then accelerates, and, finally, becomes slow again as the process is completed. For a constant strain rate, Kinetics of DRX can be expressed as follows [27]:

$$
X_{\mathrm{drx}}=1-\exp \left(-k_{\mathrm{drx}}\left(\frac{\varepsilon-\varepsilon_{c}}{\varepsilon_{p}}\right)^{n_{\mathrm{drx}}}\right),
$$

where $X_{\mathrm{drx}}$ is the dynamic recrystallization fraction, $k_{\mathrm{drx}}$ and $n_{\mathrm{drx}}$ are dynamic recrystallization parameters depending on chemical composition and hot deformation conditions, and $\varepsilon, \varepsilon_{c}$, and $\varepsilon_{p}$ are the true strain, the critical strain, and the peak strain, respectively. The DRX volume fraction under different deformation conditions can be determined by either quantitative metallographic measurement or flow curve analysis. Flow curve analysis is a simpler and quicker method compared to quantitative metallographic measurement, as the latter needs a large quantity of samples to be examined and it can be difficult to precisely ascertain the new grains [28]. Here, to determine the progress of dynamic recrystallization fraction $\left(X_{\mathrm{drx}}\right)$, the following expression is employed [29]:

$$
X_{\mathrm{drx}}=\frac{\sigma_{W H}-\sigma}{\sigma_{s}-\sigma_{s s}}\left(\varepsilon \geq \varepsilon_{c}\right),
$$

where $\sigma_{W H}$ denotes the flow stress if dynamic recovery is the only softening mechanism, $\sigma_{s}$ is the saturation stress 


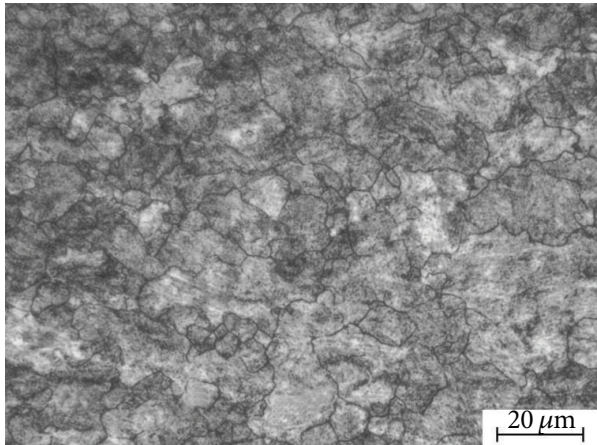

(a)

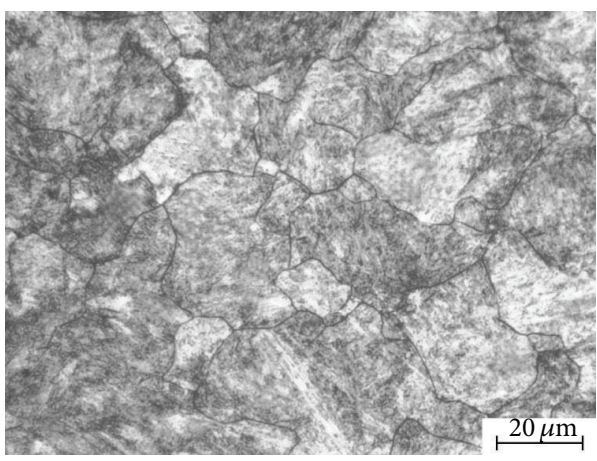

(c)

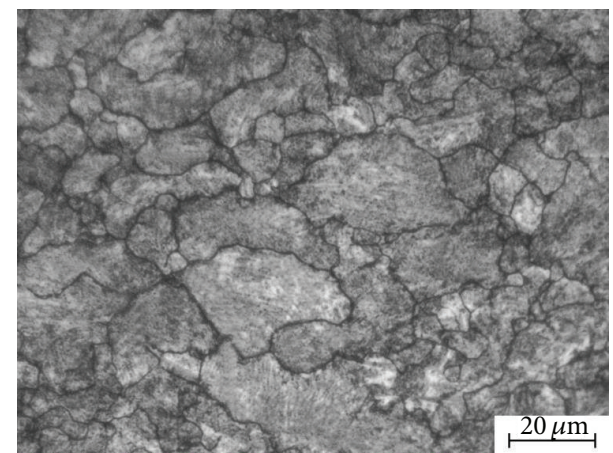

(b)

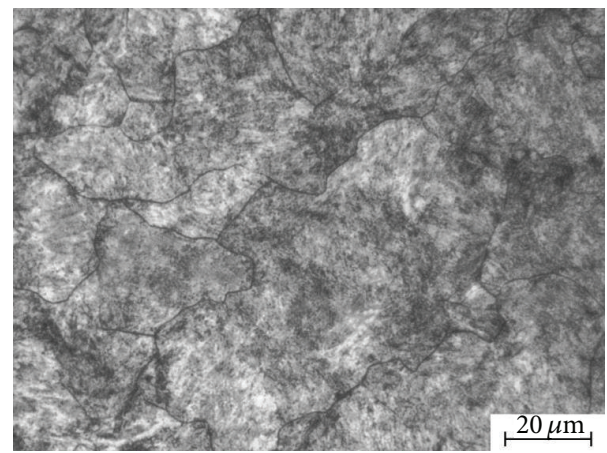

(d)

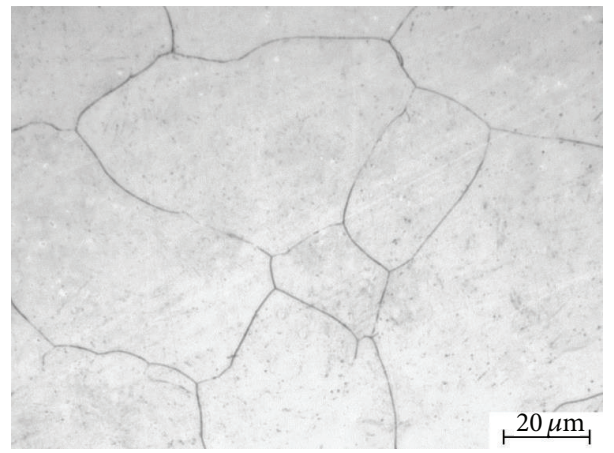

(e)

Figure 12: The microstructure of specimens deformed at (a) $T=950^{\circ} \mathrm{C}, \dot{\varepsilon}=0.01 \mathrm{~s}^{-1}$, (b) $T=1000^{\circ} \mathrm{C}, \dot{\varepsilon}=0.01 \mathrm{~s}^{-1}$, (c) $T=1050^{\circ} \mathrm{C}, \dot{\varepsilon}=0.01 \mathrm{~s}^{-1}$, (d) $T=1100^{\circ} \mathrm{C}, \dot{\varepsilon}=0.01 \mathrm{~s}^{-1}$, and (e) $T=1150^{\circ} \mathrm{C}, \dot{\varepsilon}=0.01 \mathrm{~s}^{-1}$.

[29], $\sigma_{s s}$ is the steady-state stress. From (23), the amount of DRX is determined by further analysis of the true stress-true strain curves of DRX (Figure 2) under different deformation conditions. The specific methods for calculating the values of $\sigma_{W H}, \sigma_{s}$, and $\sigma_{s s}$ can be found in Dehghan-Manshadi et al.s work [28]. Combining (22) and (23), $k_{\mathrm{drx}}$ and $n_{\mathrm{drx}}$ are determined. As can be seen from Figure 13, there is a linear relationship between $\ln \left(-\ln \left(1-X_{\mathrm{drx}}\right)\right)$ and $\ln \left(\left(\varepsilon-\varepsilon_{c}\right) / \varepsilon_{p}\right)$ under different deformation conditions; therefore, the resulting equation for $X_{\mathrm{drx}}$ is given by

$$
\begin{gathered}
X_{\mathrm{drx}}=0 \quad \varepsilon<\varepsilon_{c} \\
X_{\mathrm{drx}}=1-\exp \left(-0.2194\left(\frac{\varepsilon-\varepsilon_{c}}{\varepsilon_{p}}\right)^{2.9764}\right) \quad \varepsilon \geq \varepsilon_{c} .
\end{gathered}
$$

The optical micrographs under the temperature of $950^{\circ} \mathrm{C}$ and the strain rate of $0.1 \mathrm{~s}^{-1}$ for the strains of $0.4,0.6$, and 0.8 are shown in Figure 14. It can be found that at strain of 0.4 DRX takes place at a relatively low level, at strain of 0.6 the volume fraction of DRX is less than $20 \%$, and at the strain of 0.8 the volume fraction of DRX is about $50 \%$. The comparison of the dynamically recrystallized volume fraction predicting by the developed kinetics model with the experimental results is shown in Figure 15, which demonstrates that the predictions are in good accordance with the experimental data.

Based on the developed kinetics equations for DRX above, the effect of deformation temperature, strain, and strain rate on the volume fraction of DRX is shown in 


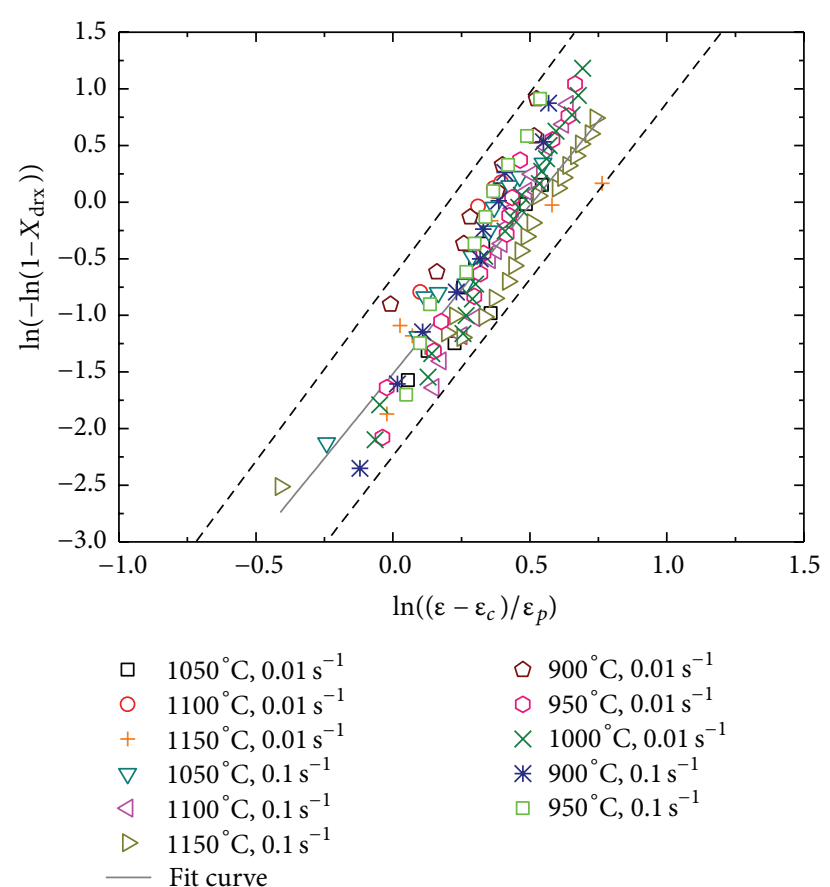

FIGURE 13: Relationship between $\ln \left(-\ln \left(1-X_{\mathrm{drx}}\right)\right)$ and $\ln \left(\left(\varepsilon-\varepsilon_{c}\right) / \varepsilon_{p}\right)$ under different deformation conditions.

Figure 16. As shown in the figure, the volume fraction of DRX increases with the increasing of the strain. For a certain strain, the volume fraction of DRX is higher at higher deformation temperature or lower strain rate. Therefore, at lower deformation temperatures and higher strain rates, DRX tends to be incomplete; in other words, the volume fraction of DRX is less than 1.

3.7. Grain Size of Complete DRX. According to the above analysis, it can be found that dynamic recrystallized grain size $\left(D_{\mathrm{drx}}\right)$ mainly depends on the deformation temperature and strain rate. In other words, the dynamic grain size is a function of $Z$ parameter alone independent of the accumulated strain. Some of $D_{\mathrm{drx}}$ and $Z$ are listed in Table 1. So $D_{\mathrm{drx}}$ is a power-law function of $Z$ parameter as follows:

$$
D_{\mathrm{drx}}=B Z^{n}
$$

where $B$ and $n$ are the materials constants. As shown in Figure 17, $B$ and $n$ are determined by regression analysis as $B=4.373 \times 10^{3}$ and $n=-0.192$.

\section{Conclusions}

The hot deformation behavior of X20Cr13 martensitic stainless steel has been investigated over a wide range of strain rate and temperature by uniaxial hot compression tests using Gleeble-1500D thermomechanical simulator. From this study, the following conclusions are drawn.

(1) The isothermal flow behaviour of X20Cr13 martensitic stainless steel is characterized by the typical

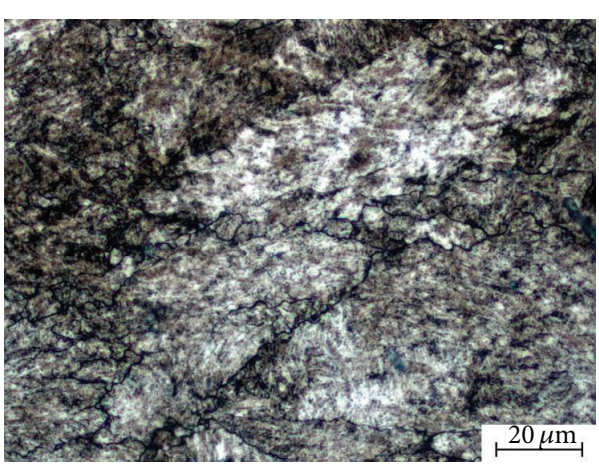

(a)

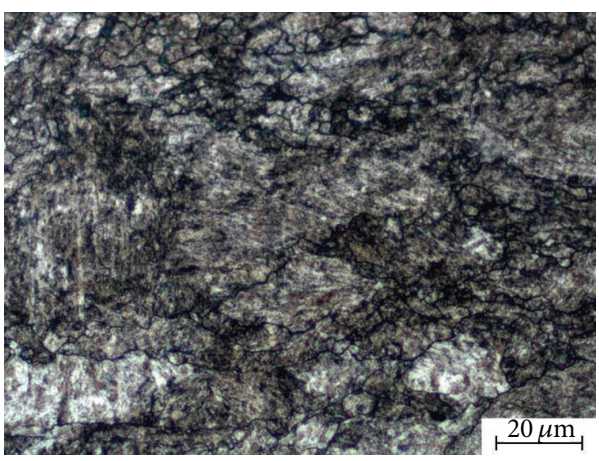

(b)

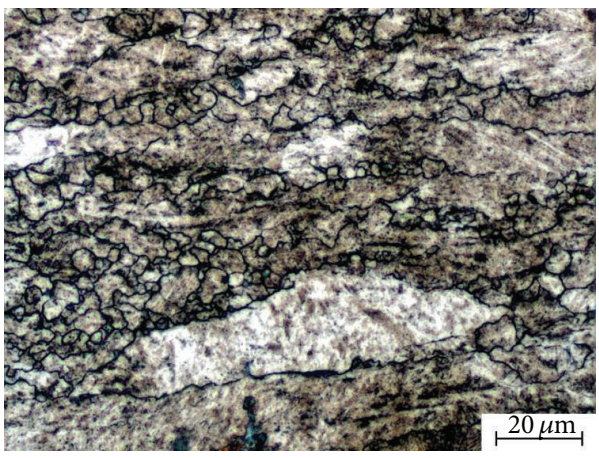

(c)

Figure 14: Micrographs of specimens deformed at $950^{\circ} \mathrm{C}$ at the strain rate of $0.1 \mathrm{~s}^{-1}$ with the strain of (a) 0.4 , (b) 0.6 , and (c) 0.8 .

dynamic recrystallization softening, whose flow curve exhibits a single peak.

(2) The activation energy for hot deformation of X20Cr13 steel is $359.4 \mathrm{~kJ} / \mathrm{mol}$.

(3) A new constitutive equation was developed which can be used to predict the flow stress up to the peak of stress-strain curve:

$$
\frac{\sigma}{\sigma_{p}}=1-\exp \left(-3.6029\left(\frac{\varepsilon}{\varepsilon_{p}}\right)^{0.4787}\right) \text {. }
$$




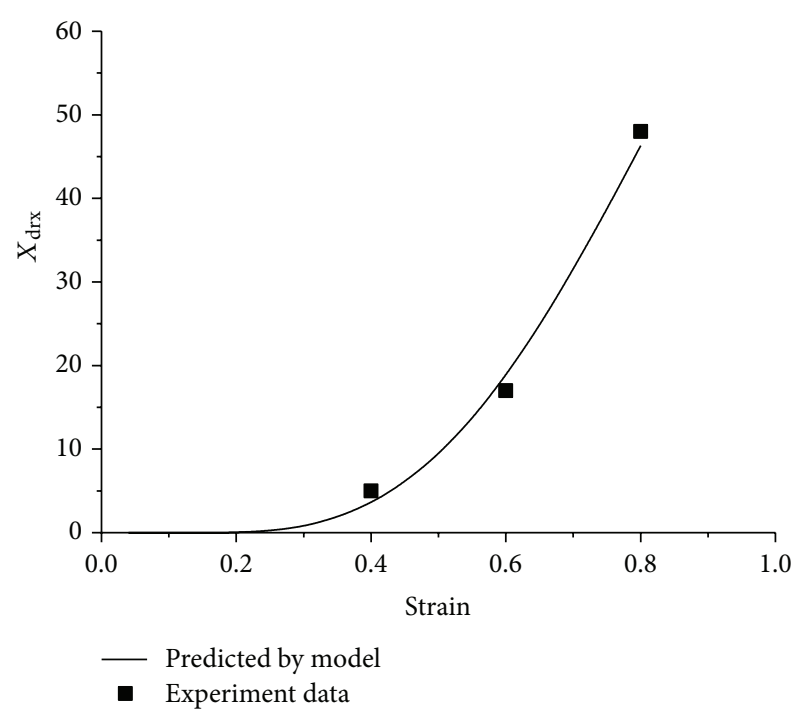

FIGURE 15: Comparison of the predicted value by the developed model with the experimental data.

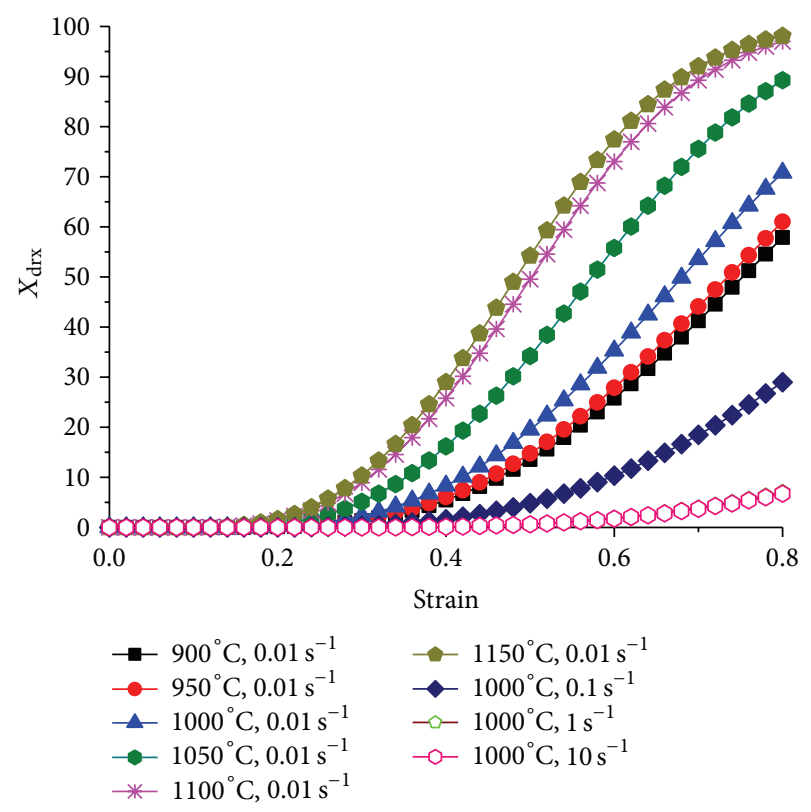

FIGURE 16: Volume fraction of DRX obtained at different temperatures and strain rates.

(4) A new equation for the critical strain for DRX was derived as follows:

$$
\frac{\varepsilon_{c}}{\varepsilon_{p}}=\left(\frac{1}{\psi \zeta}\right)^{1 / \zeta}
$$

TABLE 1: The values of $Z$ and $D_{\mathrm{drx}}$ under different deformation conditions.

\begin{tabular}{lccc}
\hline $\begin{array}{l}\text { Temperature } \\
\left({ }^{\circ} \mathrm{C}\right)\end{array}$ & Strain rate $\left(\mathrm{s}^{-1}\right)$ & $\begin{array}{c}\text { Zener-Hollomon } \\
\text { parameter }\end{array}$ & $D_{\mathrm{drx}}(\mu \mathrm{m})$ \\
\hline 900 & 0.001 & $9.939 \times 10^{12}$ & 17 \\
950 & 0.001 & $2.205 \times 10^{12}$ & 25 \\
1000 & 0.001 & $5.504 \times 10^{11}$ & 30 \\
1100 & 0.001 & $4.646 \times 10^{10}$ & 48 \\
1150 & 0.001 & $1.538 \times 10^{10}$ & 75 \\
1000 & 0.01 & $5.504 \times 10^{12}$ & 24 \\
1050 & 0.01 & $1.526 \times 10^{12}$ & 31 \\
1100 & 0.01 & $4.646 \times 10^{11}$ & 37 \\
1150 & 0.01 & $1.538 \times 10^{11}$ & 59 \\
\hline
\end{tabular}

(5) The DRX kinetics equation for the test steel was developed.

(6) Optical microscopy observations show that the DRX grain size decreases as the $Z$ parameter increases. The relation between the recrystallized grain size and $Z$ parameter was proposed on the basis of the grain size measurements.

\section{Appendices}

\section{A. The MATLABA Program for the Calculation of $\psi$ and $\zeta$}

See Algorithm 1.

\section{B. The Derivations Process of Equation (19)}

From (1), the following formula can be derived:

$$
\begin{aligned}
\theta & =\frac{d \sigma}{d \varepsilon}=\sigma_{p}\left(-\exp \left(\psi\left(\frac{\varepsilon}{\varepsilon_{p}}\right)^{\zeta}\right)\right)^{\prime} \\
& =-\sigma_{p} \exp \left(\psi\left(\frac{\varepsilon}{\varepsilon_{p}}\right)^{\zeta}\right)(\zeta \psi)\left(\frac{\varepsilon}{\varepsilon_{p}}\right)^{\zeta-1} \frac{1}{\varepsilon_{p}} \\
& \Longrightarrow \theta=\frac{-\sigma_{p} \zeta \psi}{\varepsilon_{p}} \exp \left(\psi\left(\frac{\varepsilon}{\varepsilon_{p}}\right)^{\zeta}\right)\left(\frac{\varepsilon}{\varepsilon_{p}}\right)^{\zeta-1} .
\end{aligned}
$$

Differentiating (B.1) with respect to stress,

$$
\begin{aligned}
\frac{d \theta}{d \sigma} & =\frac{d \theta}{d \varepsilon} \cdot \frac{d \varepsilon}{d \sigma}=\frac{d \theta / d \varepsilon}{\theta} \\
& =\frac{\left(\left(-\sigma_{p} \zeta \psi / \varepsilon_{p}\right) \exp \left(\psi\left(\varepsilon / \varepsilon_{p}\right)^{\zeta}\right)\left(\varepsilon / \varepsilon_{p}\right)^{\zeta-1}\right)^{\prime}}{\left(-\sigma_{p} \zeta \psi / \varepsilon_{p}\right) \exp \left(-\psi\left(\varepsilon / \varepsilon_{p}\right)\right)^{\zeta}\left(\psi\left(\varepsilon / \varepsilon_{p}\right)\right)^{\zeta-1}}
\end{aligned}
$$




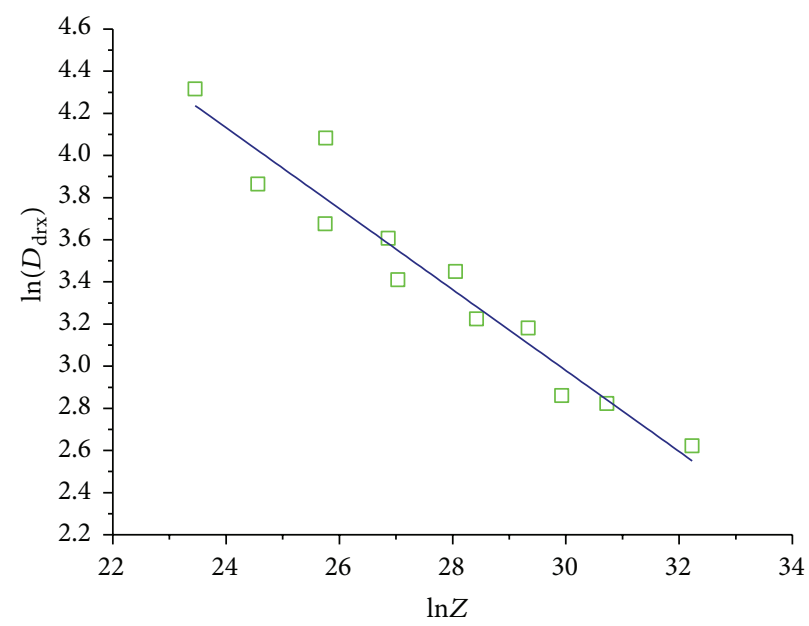

$\square \quad$ Experimental data

Linear fit

\begin{tabular}{|l|l|l|l|}
\hline Equation & $y=a+b * x$ & & \\
\hline Adj. $R^{2}$ & 0.92871 & & \\
\hline & & Value & Standard error \\
\hline $\ln G Z$ & Intercept & 8.74359 & 0.44449 \\
\hline $\ln G Z$ & Slope & -0.19214 & 0.016 \\
\hline
\end{tabular}

Figure 17: Relationship between $\ln \left(D_{\text {drx }}\right)$ and $\ln Z$.

$=\frac{-\sigma_{p} \zeta \psi}{\varepsilon_{p}}\left(\left(\exp \left(\psi\left(\frac{\varepsilon}{\varepsilon_{p}}\right)^{\zeta}\right)\right)^{\prime}\left(\frac{\varepsilon}{\varepsilon_{p}}\right)^{\zeta-1}\right.$

$\left.+\exp \left(\psi\left(\frac{\varepsilon}{\varepsilon_{p}}\right)^{\zeta}\right)\left(\left(\frac{\varepsilon}{\varepsilon_{p}}\right)^{\zeta-1}\right)^{\prime}\right)$

$\times\left(\frac{-\sigma_{p} \zeta \psi}{\varepsilon_{p}} \exp \left(\psi \frac{\varepsilon}{\varepsilon_{p}}\right)^{\zeta}\left(\psi \frac{\varepsilon}{\varepsilon_{p}}\right)^{\zeta-1}\right)^{-1}$

$=\frac{-\sigma_{p} \zeta \psi}{\varepsilon_{p}}$

$\times\left(\exp \left(\psi\left(\frac{\varepsilon}{\varepsilon_{p}}\right)^{\zeta}\right)(\psi \zeta)\left(\frac{\varepsilon}{\varepsilon_{p}}\right)^{\zeta-1} \frac{1}{\varepsilon_{p}}\left(\frac{\varepsilon}{\varepsilon_{p}}\right)^{\zeta-1}\right.$

$\left.+\exp \left(\psi\left(\frac{\varepsilon}{\varepsilon_{p}}\right)^{\zeta}\right)(\zeta-1)\left(\frac{\varepsilon}{\varepsilon_{p}}\right)^{\zeta-2} \frac{1}{\varepsilon_{p}}\right)$

$\times\left(\frac{-\sigma_{p} \zeta \psi}{\varepsilon_{p}} \exp \left(\psi\left(\frac{\varepsilon}{\varepsilon_{p}}\right)^{\zeta}\right)\left(\frac{\varepsilon}{\varepsilon_{p}}\right)^{\zeta-1}\right)^{-1}$

$\frac{d \theta}{d \sigma}=\frac{\psi \zeta}{\varepsilon_{p}}\left(\frac{\varepsilon}{\varepsilon_{p}}\right)^{\zeta-1}+\frac{(\zeta-1)}{\varepsilon_{p}}\left(\frac{\varepsilon}{\varepsilon_{p}}\right)^{-1}$
Differentiating (B.2) with respect to stress,

$$
\begin{aligned}
\frac{d^{2} \theta}{d \sigma^{2}} & =\frac{d(d \theta / d \sigma) / d \varepsilon}{\theta} \\
& =\frac{\left(\left(\psi \zeta / \varepsilon_{p}\right)\left(\varepsilon / \varepsilon_{p}\right)^{\zeta-1}+\left((\zeta-1) / \varepsilon_{p}\right)\left(\varepsilon / \varepsilon_{p}\right)^{-1}\right)^{\prime}}{\left(\sigma_{p} \zeta \psi / \varepsilon_{p}\right) \exp \left(\psi\left(\varepsilon / \varepsilon_{p}\right)^{\zeta}\right)\left(\varepsilon / \varepsilon_{p}\right)^{\zeta-1}} \\
& \Longrightarrow \frac{d^{2} \theta}{d \sigma^{2}} \\
& =\frac{\left(\psi \zeta(\zeta-1) / \varepsilon_{p}^{2}\right)\left(\varepsilon / \varepsilon_{p}\right)^{\zeta-2}-\left((\zeta-1) / \varepsilon_{p}^{2}\right)\left(\varepsilon / \varepsilon_{p}\right)^{-2}}{\left(\sigma_{p} \zeta \psi / \varepsilon_{p}\right) \exp \left(\psi\left(\varepsilon / \varepsilon_{p}\right)^{\zeta}\right)\left(\varepsilon / \varepsilon_{p}\right)^{\zeta-1}} .
\end{aligned}
$$

Let the second differential be zero. By simplifying, the final form is

$$
\begin{aligned}
& \frac{\psi \zeta(\zeta-1)}{\varepsilon_{p}^{2}}\left(\frac{\varepsilon_{c}}{\varepsilon_{p}}\right)^{\zeta-2}-\frac{(\zeta-1)}{\varepsilon_{p}^{2}}\left(\frac{\varepsilon_{c}}{\varepsilon_{p}}\right)^{-2}=0 \\
& \Longrightarrow \frac{\varepsilon_{c}}{\varepsilon_{p}}=\left(\frac{1}{\psi \zeta}\right)^{1 / \zeta} .
\end{aligned}
$$

\section{Conflict of Interests}

The authors declare that there is no conflict of interests regarding the publication of this paper. 


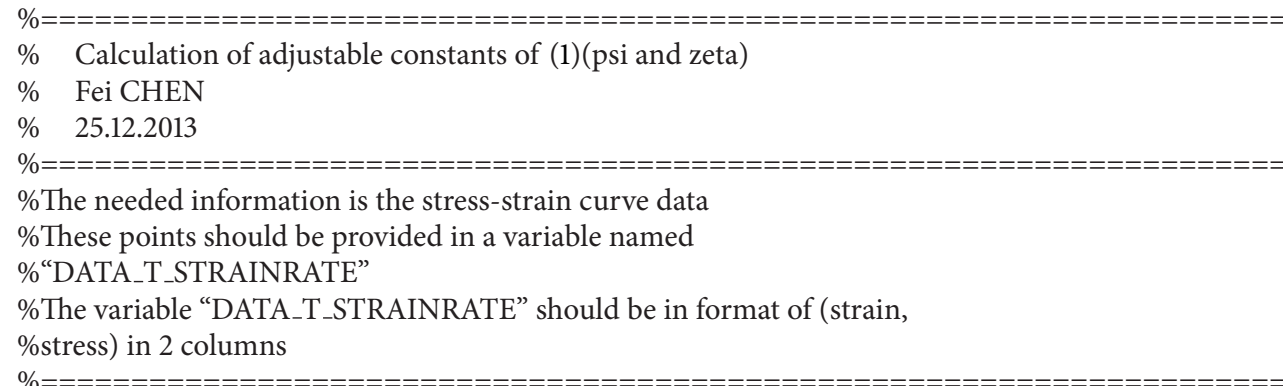

clc;

clear all;

$\mathrm{a}=\operatorname{load}($ 'DATA_T_STRAINRATE'); \% reading the experimental data

$\mathrm{N}=$ size(a); $\mathrm{N}=\mathrm{N}(1) ; \%$ Number of rows

$\mathrm{s} 0=\mathrm{a}(1,2) ; \%$ Value of initial stress

$\mathrm{sp}=\max (\mathrm{a}) ; \mathrm{sp}=\mathrm{sp}(2) ; \%$ Value of peak stress

$\mathrm{Q}=\operatorname{size}(\mathrm{a}) ; \mathrm{Q}=\mathrm{Q}(1) ; \%$ Number of rows

for $\mathrm{i}=1: \mathrm{Q}$;

if $(\mathrm{a}(\mathrm{i}, 2)==\mathrm{sp})$

$\mathrm{ep}=\mathrm{a}(\mathrm{i}, 1) ; \%$ Value of peak strain

$\mathrm{M}=\mathrm{i}$;

end

end

for $i=1: M$

$b(i, 1)=a(i, 1)$;

$b(i, 2)=a(i, 2)$;

end

$\mathrm{xl}=\mathrm{b}(:, 1)$;

$\mathrm{yl}=\mathrm{b}(:, 2)$;

for $\mathrm{i}=1: \mathrm{M}$

$c(i, 1)=a(i, 1) / e p ;$

$c(i, 2)=a(i, 2) / s p ;$

end

$\mathrm{x} 2=\mathrm{c}(:, 1)$;

$\mathrm{y} 2=\mathrm{c}(:, 2)$

$\mathrm{k} 0=[0.001,0.001]$;

$\mathrm{x}=0: 0.001: 1$;

$\mathrm{f} 1=@(\mathrm{k}, \mathrm{x})(1-\exp (\mathrm{k}(1) *(\mathrm{x}) . \wedge \mathrm{k}(2)))$;

for $\mathrm{i}=1: 1000$

$\mathrm{k}=$ lsqcurvefit $(\mathrm{f} 1, \mathrm{k} 0, \mathrm{x} 2, \mathrm{y} 2) ; \%$ the method of least squares

$\mathrm{k} 0=\mathrm{k}$;

end

$\mathrm{y}=1-\exp \left(\mathrm{k}(1) *(\mathrm{x}) .^{\wedge} \mathrm{k}(2)\right)$;

for $\mathrm{i}=1: \mathrm{M}$

$\mathrm{d}(\mathrm{i}, 1)=\mathrm{b}(\mathrm{i}, 1)$;

$\mathrm{d}(\mathrm{i}, 2)=\mathrm{sp} *(1-\exp (\mathrm{k}(1) * \mathrm{c}(\mathrm{i}, 1) . \wedge \mathrm{k}(2)))$;

end

$\% \mathrm{psi}=\mathrm{k}(1)$

\%zeta $=\mathrm{k}(2)$

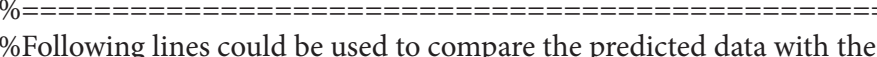

\%experimental data

$\%=====$
$\% \times 3=\mathrm{d}(: 11) ;$

$\% \mathrm{y} 3=\mathrm{d}(:, 2)$

\%subplot(1,2,1),plot(x2,y2,'b:*')

\%hold on

\%subplot(1,2,1),plot(x,y,'g:+');

$\%$ hold off

\%subplot(1,2,2),plot(x1,yl,'b:*') 


\author{
\%hold on \\ \%subplot(1,2,2),plot(x3,y3,'g:+') \\ \%hold off
}

Algorithm 1

\section{Acknowledgments}

The authors gratefully acknowledge the financial support from the National Science and Technology Major Project of China (Grant no. 2012ZX04012011), the National Basic Research Program of China (Gran no. 2011CB012903), the China Postdoctoral Science Foundation (Grant no. 2013M531171), and the Shanghai Jiaotong University Postdoctoral Science Foundation.

\section{References}

[1] E. Brünger, X. Wang, and G. Gottstein, "Nucleation mechanisms of dynamic recrystallization in austenitic steel alloy 800H," Scripta Mater, vol. 38, no. 12, pp. 1843-1849, 1998.

[2] E. I. Poliak and J. J. Jonas, "Initiation of dynamic recrystallization in constant strain rate hot deformation," ISIJ International, vol. 43, no. 5, pp. 684-691, 2003.

[3] E. I. Poliak and J. J. Jonas, "A one-parameter approach to determining the critical conditions for the initiation of dynamic recrystallization," Acta Materialia, vol. 44, no. 1, pp. 127-136, 1996.

[4] T. Sakai and J. J. Jonas, "Overview no. 35 dynamic recrystallization: mechanical and microstructural considerations," Acta Metallurgica, vol. 32, no. 2, pp. 189-209, 1984.

[5] A. Cingara and H. J. McQueen, "New formula for calculating flow curves from high temperature constitutive data for 300 austenitic steels," Journal of Materials Processing Technology, vol. 36, no. 1, pp. 31-42, 1992.

[6] A. Najafizadeh and J. J. Jonas, "Predicting the critical stress for initiation of dynamic recrystallization," ISIJ International, vol. 46, no. 11, pp. 1679-1684, 2006.

[7] H. Mirzadeh and A. Najafizadeh, "Prediction of the critical conditions for initiation of dynamic recrystallization," Materials and Design, vol. 31, no. 3, pp. 1174-1179, 2010.

[8] H. Mirzadeh, J. M. Cabrera, and A. Najafizadeh, "Modeling and prediction of hot deformation flow curves," Metallurgical and Materials Transactions A, vol. 43, no. 1, pp. 108-123, 2012.

[9] J. J. Jonas, C. Ghosh, X. Quelennec, and V. V. Basabe, "The critical strain for dynamic transformation in hot deformed austenite," ISIJ International, vol. 53, no. 1, pp. 145-151, 2013.

[10] S. Solhjoo, "Determination of flow stress and the critical strain for the onset of dynamic recrystallization using a hyperbolic tangent function," Materials and Design, vol. 54, pp. 390-393, 2014.

[11] H. Mirzadeh, J. M. Cabrera, A. Najafizadeh, and P. R. Calvillo, "EBSD study of a hot deformed austenitic stainless steel," Materials Science and Engineering A, vol. 538, pp. 236-245, 2012.

[12] M. R. Barnett, G. L. Kelly, and P. D. Hodgson, "Predicting the critical strain for dynamic recrystallization using the kinetics of static recrystallization," Scripta Materialia, vol. 43, no. 4, pp. 365-369, 2000.
[13] G. Gottstein, M. Frommert, M. Goerdeler, and N. Schäfer, "Prediction of the critical conditions for dynamic recrystallization in the austenitic steel $800 \mathrm{H}$," Materials Science and Engineering A, vol. 387-389, no. 1-2, pp. 604-608, 2004.

[14] N. R. Baddoo, "Stainless steel in construction: a review of research, applications, challenges and opportunities," Journal of Constructional Steel Research, vol. 64, no. 11, pp. 1199-1206, 2008.

[15] B. S. Mann and J. Mater, "Laser treatment of textured X20Cr13 stainless steel to improve water droplet erosion resistance of LPST blades and LP bypass Valves," Journal of Materials Engineering and Performance, vol. 22, no. 12, pp. 3699-3707, 2013.

[16] ASTM E209, Annual Bood of ASTM Standards, vol. 3, ASTM International, 2010.

[17] ASTM standard E112-88, ASTM, Philadelphia, Pa, USA, 1988.

[18] F. Chen, Z. Cui, and S. Chen, "Recrystallization of $30 \mathrm{Cr} 2 \mathrm{Ni} 4 \mathrm{MoV}$ ultra-super-critical rotor steel during hot deformation. Part I: dynamic recrystallization," Materials Science and Engineering A, vol. 528, no. 15, pp. 5073-5080, 2011.

[19] F. Chen, Z. S. Cui, D. S. Sui et al., "Recrystallization of 30 $\mathrm{Cr}_{2} \mathrm{Ni}_{4} \mathrm{MoV}$ ultra-super-critical rotor steel during hot deformation. Part III: metadynamic recrystallization," Materials Science and Engineering A, vol. 540, pp. 46-54, 2012.

[20] A. Dehghan-Manshadi and P. D. Hodgson, "Dynamic recrystallization of austenitic stainless steel under multiple peak flow behaviours," ISIJ International, vol. 47, no. 12, pp. 1799-1803, 2007.

[21] C. Zener and J. H. Hollomon, "Effect of strain rate upon plastic flow of steel," Journal of Applied Physics, vol. 15, no. 1, pp. 22-32, 1944.

[22] H. J. McQueen and N. D. Ryan, "Constitutive analysis in hot working," Materials Science and Engineering A, vol. 322, no. 1-2, pp. 43-63, 2002.

[23] H. Mirzadeh, J. M. Cabrera, J. M. Prado, and A. Najafizadeh, "Hot deformation behavior of a medium carbon microalloyed steel," Materials Science and Engineering A, vol. 528, no. 10-11, pp. 3876-3882, 2011.

[24] M. Shaban and B. Eghbali, "Determination of critical conditions for dynamic recrystallization of a microalloyed steel," Materials Science and Engineering A, vol. 527, no. 16-17, pp. 4320-4325, 2010.

[25] N. D. Ryan and H. J. McQueen, "Dynamic softening mechanisms in 304 austenitic stainless steel," Canadian Metallurgical Quarterly, vol. 29, no. 2, pp. 147-162, 1990.

[26] A. M. Elwazri, P. Wanjara, and S. Yue, "Critical condition for dynamic recrystallisation of high carbon steels," Materials Science \& Technology, vol. 20, no. 11, pp. 1469-1473, 2004.

[27] L. X. Kong, P. D. Hodgson, and B. Wang, "Development of constitutive models for metal forming with cyclic strain softening," Journal of Materials Processing Technology, vol. 89-90, pp. 44-50, 1999. 
[28] A. Dehghan-Manshadi, M. R. Barnett, and P. D. Hodgson, "Hot deformation and recrystallization of austenitic stainless steel: part I. dynamic recrystallization," Metallurgical and Materials Transactions A: Physical Metallurgy and Materials Science, vol. 39, no. 6, pp. 1359-1370, 2008.

[29] A. Laasraoui and J. J. Jonas, "Prediction of steel flow stresses at high temperatures and strain rates," Metallurgical Transactions A, vol. 22, no. 7, pp. 1545-1558, 1991. 

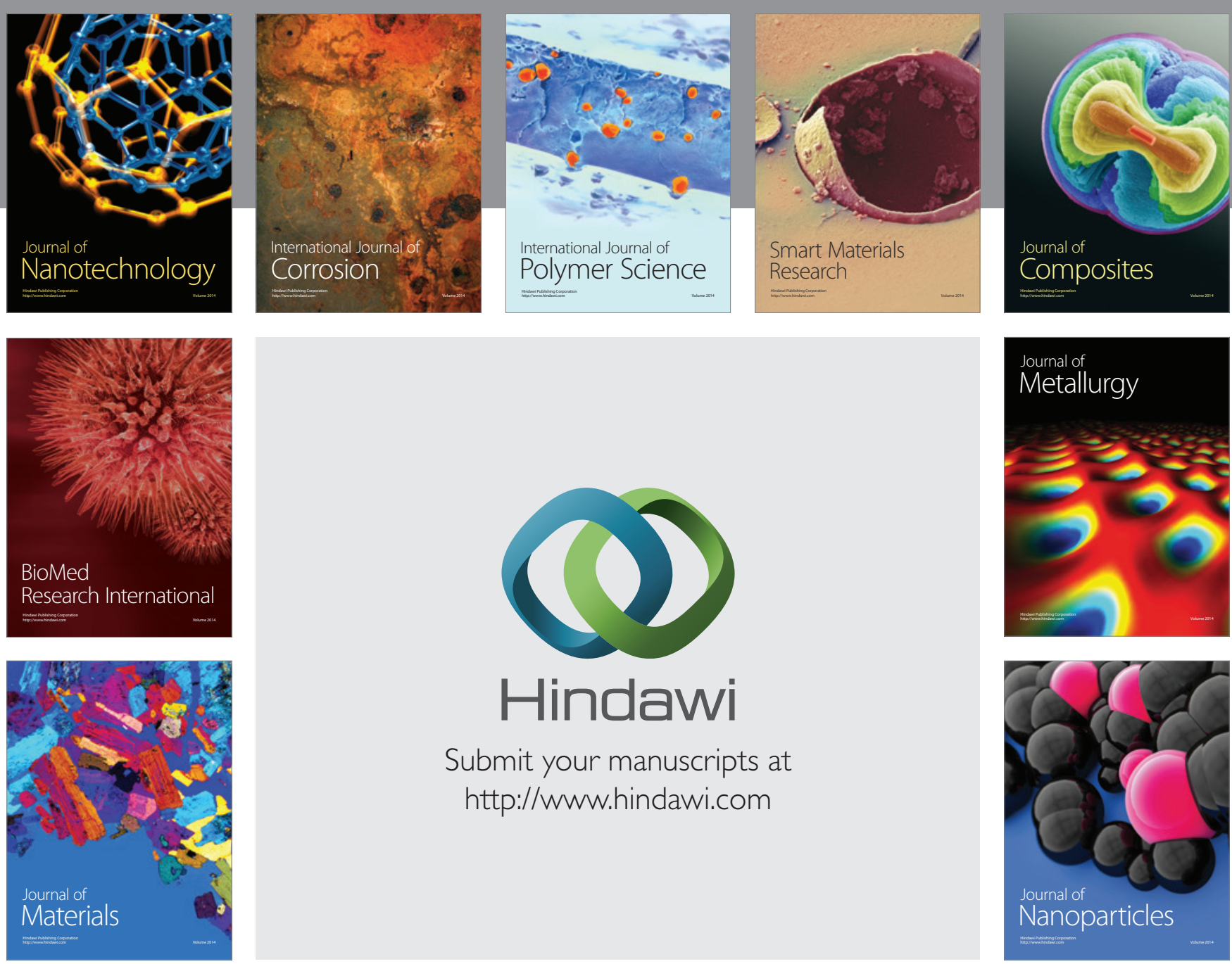

Submit your manuscripts at http://www.hindawi.com
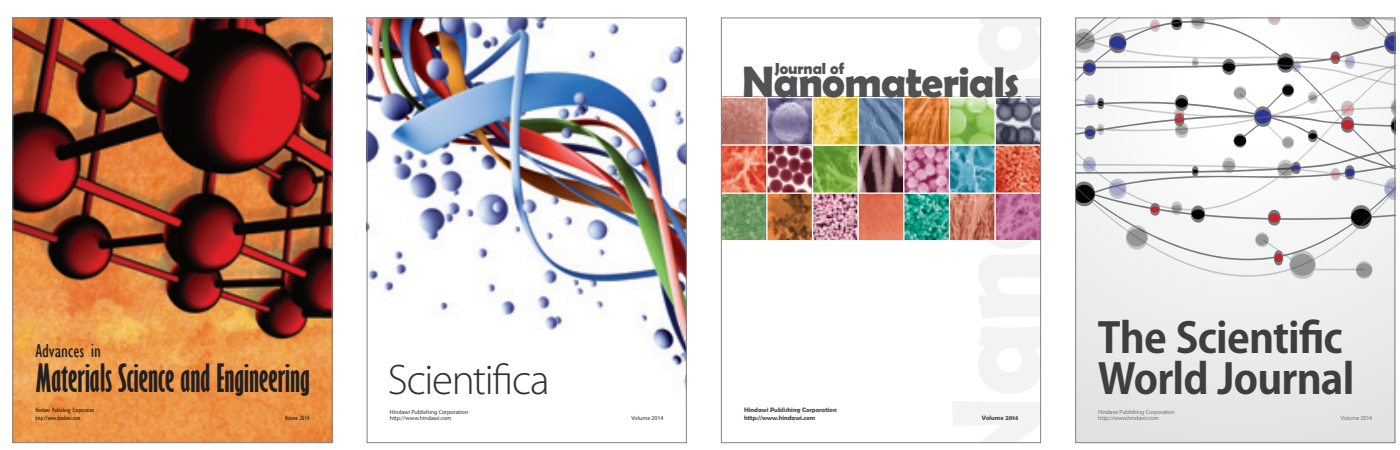

\section{The Scientific World Journal}
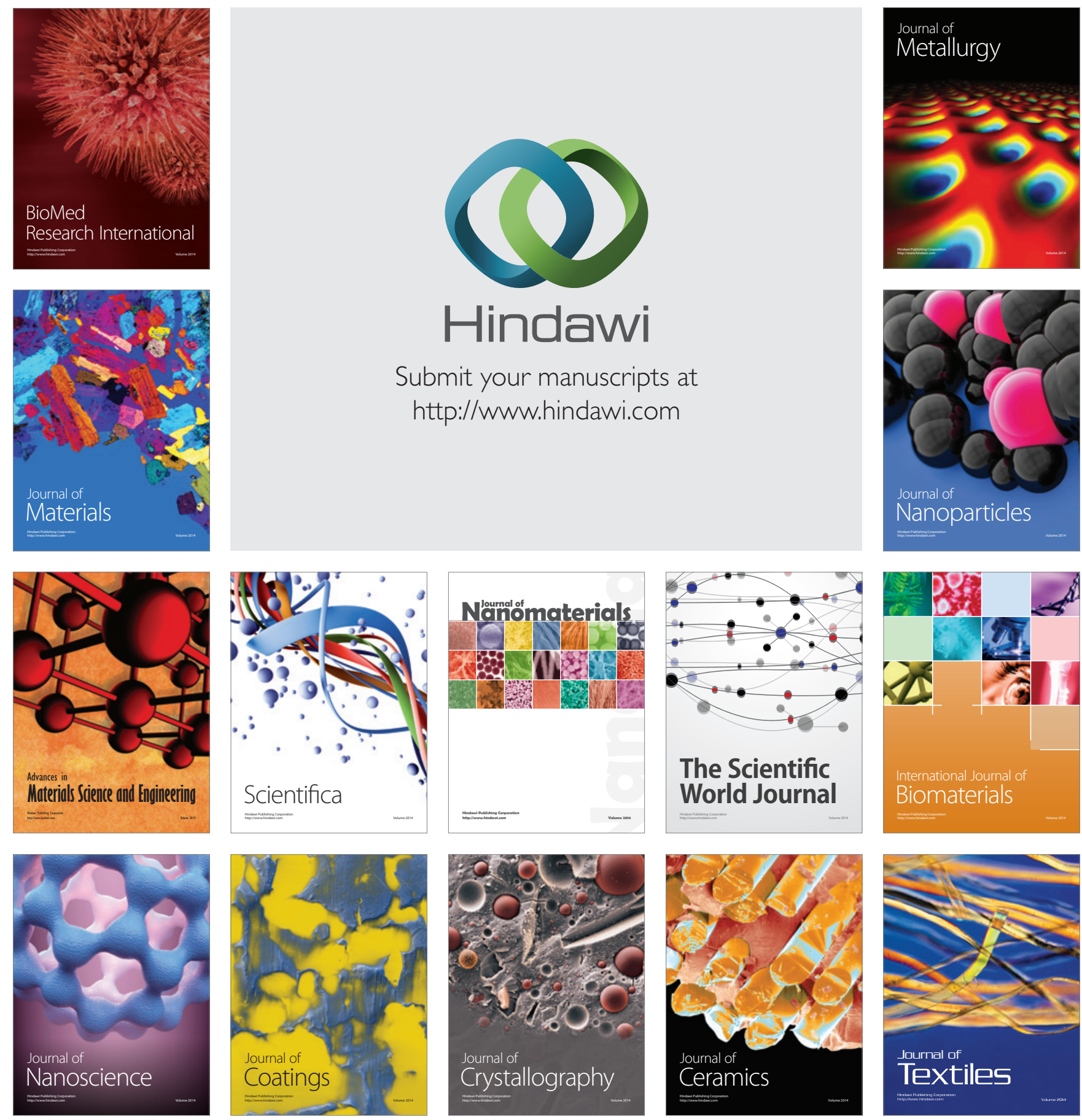